\title{
The Role of Neuromuscular Control of Postural and Core Stability in Functional Movement and Athlete Performance
}

\author{
Erika Zemková ${ }^{1,2,3 *}$ and Ludmila Zapletalová ${ }^{3}$ \\ ${ }^{1}$ Department of Biological and Medical Sciences, Faculty of Physical Education and Sport, Comenius University \\ in Bratislava, Bratislava, Slovakia, ${ }^{2}$ Sports Technology Institute, Faculty of Electrical Engineering and Information Technology, \\ Slovak University of Technology, Bratislava, Slovakia, ${ }^{3}$ Faculty of Health Sciences, University of Ss. Cyril and Methodius \\ in Trnava, Trnava, Slovakia
}

Balance and core stabilization exercises have often been associated with improved athlete performance and/or decreased incidence of injuries. While these exercises seem to be efficient in the prevention of injuries, there is insufficient evidence regarding their role in sport-specific performance and related functional movements. The aim of this scoping review is (1) to map the literature that investigates whether currently available variables of postural and core stability are functionally related to athlete performance in sports with high demands on body balance and spinal posture and (2) to identify gaps in

OPEN ACCESS

Edited by: Giuseppe Marcolin, University of Padua, Italy

Reviewed by: Dale Wilson Chapman, Curtin University, Australia Mathew Hill, Coventry University, United Kingdom

*Correspondence: Erika Zemková erika.zemkova@uniba.sk orcid.org/0000-0003-0938-5691

Specialty section:

This article was submitted to Exercise Physiology, a section of the journa

Frontiers in Physiology

Received: 15 October 2021

Accepted: 07 January 2022

Published: 24 February 2022

Citation:

Zemková E and Zapletalová L (2022) The Role of Neuromuscular Control of Postural and Core Stability in Functional Movement and Athlete

Performance.

Front. Physiol. 13:796097. doi: 10.3389/fphys.2022.796097 the literature and suggest further research on this topic. The literature search conducted on MEDLINE, Scopus, Web of Science, PubMed, and Cochrane Library databases was completed by Google Scholar, SpringerLink, and Elsevier. Altogether 21 articles met the inclusion criteria. Findings revealed that postural stability plays an important role in performance in archery, biathlon, gymnastics, shooting, and team sports (e.g., basketball, hockey, soccer, tennis). Also core stability and strength represent an integral part of athlete performance in sports based on lifting tasks and trunk rotations. Variables of these abilities are associated with performance-related skills in cricket, cycling, running, and team sports (e.g., baseball, football, hockey, netball, soccer, tennis). Better neuromuscular control of postural and core stability contribute to more efficient functional movements specific to particular sports. Training programs incorporating general and sport-specific exercises that involve the use of postural and core muscles showed an improvement of body balance, back muscle strength, and endurance. However, there is controversy about whether the improvement in these abilities is translated into athletic performance. There is still a lack of research investigating the relationship of body balance and stability of the core with sport-specific performance. In particular, corresponding variables should be better specified in relation to functional movements in sports with high demands on postural and core stability. Identifying the relationship of passive, active, and neural mechanisms underlying balance control and spinal posture with athlete performance would provide a basis for a multifaced approach in designing training and testing tools addressing postural and core stability in athletes under sport-specific conditions.

Keywords: body balance, core stabilization, neuromuscular functions, spinal stability, sport-specific performance 


\section{INTRODUCTION}

Postural and core stability is critical to almost all movements in sport (Sharrock et al., 2011), particularly when maintaining balance on an uneven surface or while responding to sudden perturbations (Zazulak et al., 2007). While most research has been devoted to the role of postural stability in athletic performance, far fewer studies have investigated the relationship between core stability and sport-specific skills.

The core that involves lumbopelvic-hip region maintains the vertebral column equilibrium within its physiological limit by reducing postural displacement after unexpected perturbations (Reeves et al., 2007). This requires instantaneous activation of the central nervous system to evoke optimal muscle recruitment for both stability and mobility. Core muscles provide the necessary stability for the production of force in the lower limbs and efficient control of body movements (Rivera, 2016). Deficiencies or imbalances in the core muscles can increase fatigue, decrease endurance, and increase the risk of injuries in athletes (Rivera, 2016).

Recently, widely promoted spine stabilization and core strengthening exercises have been seen to improve postural and core stability and/or reduce back problems in athletes (Akuthota et al., 2008). These exercises seem to be efficient in the prevention and rehabilitation of back pain, lumbar spine injuries, or other musculoskeletal disorders. However, there is a lack of evidence regarding their effectiveness for improvements of functional movements and consequently also athletic performance. This is mainly due to a limited number of appropriate tests evaluating postural and core stability that would be able to provide deeper insights into the understanding of exercise-induced changes in neuromuscular functions under sport-specific conditions.

Currently, motion analysis and accelerometry recordings allow monitoring of head, trunk, and limb movements and provide useful data for a complete assessment of postural and core stability during a variety of functional movements. Measurement of postural sway using accelerometry is strongly related to task-based variables (Whitney et al., 2011). The accelerometry combined with stochastic dynamics quantifies the time-varying structure of postural sway pattern (Lamoth et al., 2009). For instance, acceleration time-series are more stable, less variable, and less regular with greater gymnastic skills (Lamoth et al., 2009).

In the study by Glofcheskie and Brown (2017), a seated balance task was used to assess trunk postural control, electromyography, and kinematics to measure neuromuscular control in response to unexpected trunk perturbations, and active trunk repositioning tasks to examine proprioceptive ability. There was an interactive relationship between postural control, trunk neuromuscular control, and trunk proprioception in athletes of different training backgrounds (Glofcheskie and Brown, 2017). More specifically, greater trunk postural control (less CoP movement), less lumbar spine angular displacement, higher muscle activation amplitudes, and faster trunk muscle activation onsets in response to unexpected trunk perturbations were found in athletes (collegiate level long-distance runners and golfers) than non-athletes (Glofcheskie and Brown, 2017).
Absolute and variable errors in trunk repositioning tasks were lower in golfers than runners and controls, which indicates their greater proprioceptive ability (Glofcheskie and Brown, 2017).

Usually, postural and core stability have been compared among athletes of different sports, their age, and/or performance level. For instance, the best body balance is found in gymnasts, then in soccer players, swimmers, physically active controls, and basketball players (Hrysomallis, 2011). Balance is related to the competition level of athletes, and the more proficient ones display better postural stability (Hrysomallis, 2011). Athletes of rifle shooting, soccer, and golf have better postural stability than their less-proficient counterparts (Hrysomallis, 2011). Paillard (2019) reported that the most successful athletes have the best postural performance, both in ecological and non-ecological postural conditions, that is, specific vs. decontextualized in relation to the sport practiced. They also have more elaborate postural strategies than those at lower competition levels (Paillard, 2019). Specific muscle synergies are of considerable value as a training strategy for hockey players who need to improve their postural stability and reduce their potential risk of injuries (Kim et al., 2018).

Balance is also associated with performance measures (Hrysomallis, 2011). Body sway measured during stance on a force plate is related to aim point fluctuation and shooting performance (Ball et al., 2003). As body sway increases, performance decreases and aim point fluctuation increases for most relationships in elite rifle shooters (Ball et al., 2003). Postural balance in the standing position is also related to the shooting accuracy, both directly and indirectly, through rifle stability (Mononen et al., 2007). Furthermore, a balance ratio (contact with floor to no contact time) during a 30-s wobble board test correlates with maximum skating speed in hockey players (Behm et al., 2005). Unipedal static balance, core strength, and stability correlate with golf performance in elite players (Wells et al., 2009). There is also a relationship between unipedal dynamic balance and the luge starting speed (Platzer et al., 2009a).

In general, practicing any kind of sport is associated with better postural stability (Andreeva et al., 2021). The center of pressure (CoP) velocity during a bipedal stance on a force platform with eyes open is lower in shooters, football players, boxers, cross-country skiers, gymnasts, runners, team sport players, wrestlers, tennis players, alpine skiers, rowers, speed skaters, and figure skaters when compared to the general population (Andreeva et al., 2021). Athletes usually display better postural stability in sport-specific conditions and sway measures may not reveal between and within-group differences when testing in a standard upright position (Zemková, 2014). There are also differences in the magnitude of postural sway increase after sport-specific exercises and the speed of its readjustment to pre-exercise level (Zemková, 2014).

Investigating the relationship of passive, active, and neural mechanisms underlying balance control and spine stabilization with sport-specific performance would provide a basis for a multifaced approach in designing training and testing tools addressing postural and core stability in athletes. The aim of this scoping review was (1) to review the existing literature that deals with sports with high demands on body balance and spinal posture and to investigate whether currently available variables 
of postural and core stability are functionally related to athletic performance and (2) to identify gaps in the literature and suggest further research on this topic.

\section{METHODS}

This article was proposed as a scoping review (Armstrong et al., 2011). The purpose was to provide an overview of the available research evidence and answer the following question: (1) Is there a relationship between postural and core stability and functional movement and/or athletic performance?

An electronic literature search was provided to analyze existing studies dealing with the role of neuromuscular control of both postural and core stability in functional movement and/or athlete performance. Studies were searched on Scopus, Web of Science, PubMed, MEDLINE, and Cochrane Library databases. This search was completed on Google Scholar, Elsevier, and SpringerLink. The articles in peer-reviewed journals were considered for analysis. References included in review articles were also searched to identify further relevant studies. If articles included overlapping data from the same or similar study, the one with the most recent publication date was analyzed. Articles or abstracts published in conference proceedings, theses, case studies, and books were excluded. Articles were also excluded if they did not contain original research or were incomplete. The inclusion criteria involved research articles that specified participants, experimental protocols, and measures relevant to this review. The literature search was limited to the English language. Articles published after 1990 were preferred. Articles were excluded if they failed to meet the eligibility criteria.

The initial search was confined to research articles closely related to the main purpose of this scoping review, that is, those dealing with the relationship between neuromuscular control of either postural or core stability and functional movement and/or athlete performance. However, this approach revealed only a limited number of articles that met the eligibility criteria. The search was, therefore, widened to investigations dealing with the effects of sport-specific and balance or the core-related exercises on functional movements and skills within a particular sport. In particular, neuromuscular mechanisms underlying these relationships were studied. This together helped us to identify gaps in the literature and formulate recommendations for further studies in this field of research.

The search and appraisal of selected studies on the basis of exclusion and inclusion criteria were performed by both authors of this review. Some concerns were related to sample size and its representativeness, incomplete information about the methods used, variables analyzed, and/or non-controlled compliance of experiments. The target population was athletes of a team and individual sports where balance and core stability play an essential role in their performance. Proposed sports were combined with the following keywords.

A combination of these terms was included in the search strategy: "postural stability" AND "core stability" AND "core endurance" AND "core strength" AND "core training" AND "body balance" AND "postural control" AND "spinal posture" AND "lumbopelvical stability" AND "athletes" AND "sportspecific exercise" AND "athletic performance" AND "functional movement," AND "neuromuscular control."

Further searches were conducted by using words from subheadings that specified the contribution of postural and core stability on performance in highly skilled athletes in comparison with those at a lower level of sport-specific skills. Following an initial screening of articles identified through database searching and assessing for their eligibility, those that failed to meet inclusion criteria were removed. Articles that investigated neuromuscular control of postural (14 out of 29) and core (7 out of 13) stability in association with functional movements and/or athlete performance were included in this scoping review. The search process phases are displayed in Figure $\mathbf{1 .}$

\section{RESULTS AND DISCUSSION}

\section{The Role of Neuromuscular Control of Postural Stability in Functional Movement and/or Athlete Performance}

Analysis of the literature revealed (Table 1) that postural stability plays an important role in functional movements and/or athlete performance in shooting (Era et al., 1996; Ball et al., 2003; Mononen et al., 2007; Ihalainen et al., 2016a,b, 2018; Lang and Zhou, 2021), gymnastics (Opala-Berdzik et al., 2021), dancing (Munzert et al., 2019), and team sports, such as soccer (Jadczak et al., 2019a,b).

\section{Shooting, Biathlon, and Archery}

The majority of studies investigated postural stability in association with shooter performance. Postural stability and stability of hold were identified as the main factors influencing air rifle shooting performance (Era et al., 1996; Konttinen et al., 1998; Ball et al., 2003). High postural stability and small gun barrel movements determine shooting performance in novice shooters (Mononen et al., 2007). High postural stability is also important in elite rifle shooters (Lang and Zhou, 2021). Specifically, CoP variables measured during stance on a force plate negatively correlate with shooting score and aiming accuracy, whereas there is a positive correlation with the stability of hold and stability of triggering (Lang and Zhou, 2021). The timing of triggering, cleanness of triggering, and aiming accuracy then influence shooting score in elite-level air rifle shooters (Ihalainen et al., 2016a). Taking together, postural stability, cleanness of triggering, aiming accuracy, and stability of hold affect performance in both training and competition situations even in athletes at high-shooting skill levels (Ihalainen et al., 2016b). Particularly, body sway is related to aim point fluctuation in shooters (Ball et al., 2003). Aim point fluctuation increases and performance decreases as body sway increases for most relationships (Ball et al., 2003). However, Spancken et al. (2021) identified that body sway does affect shot score in national- and elite-level athletes in both small-bore and air-rifle shooting, whereas aiming time, aiming accuracy, and horizontal rifle stability influence shot score in national-level air-rifle athletes. A higher Romberg quotient in 

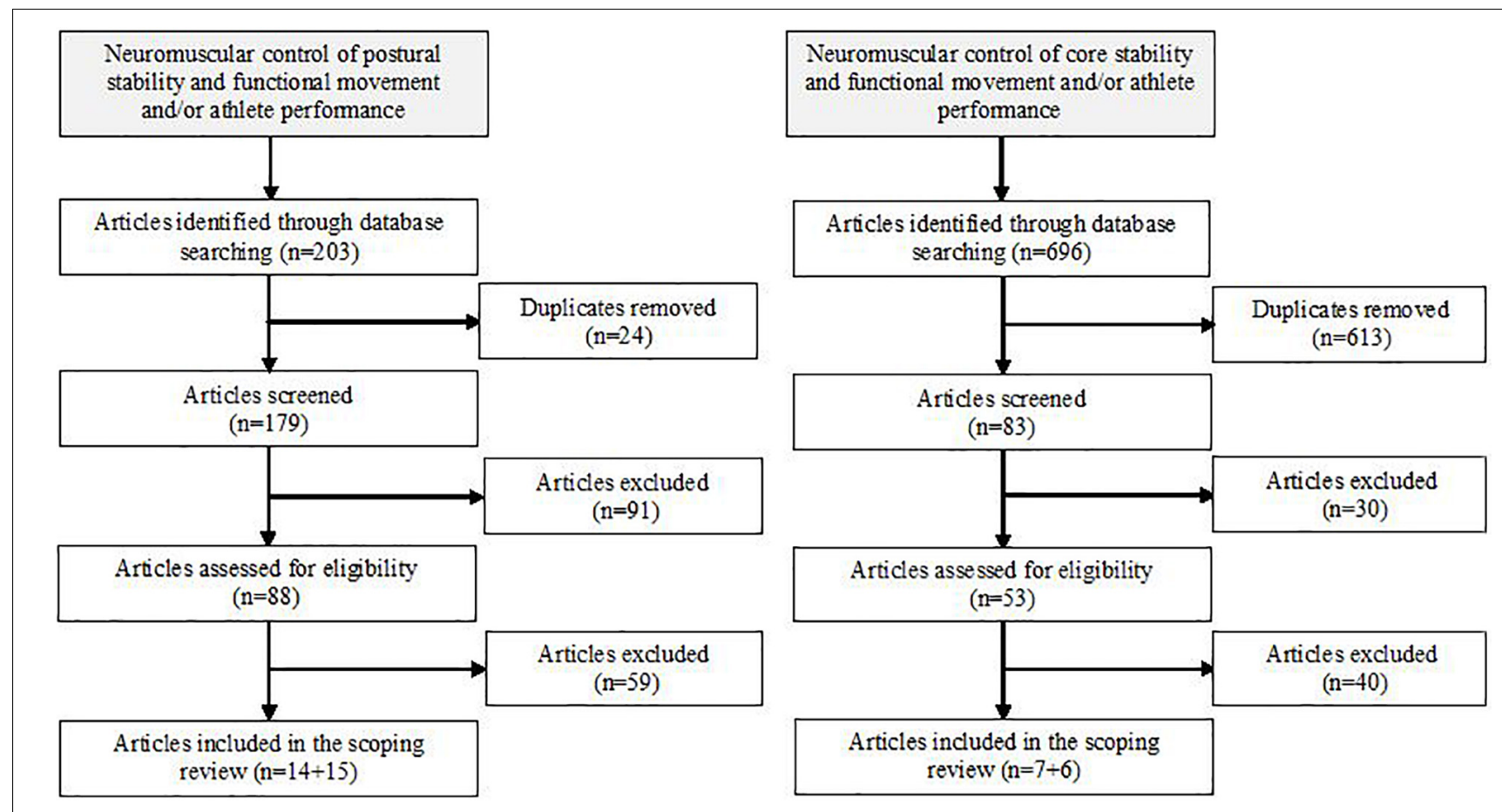

FIGURE 1 | Flow chart showing the literature search phases.

shooters than in controls indicates that they use an increased amount of vestibular and proprioceptive cues to stabilize their posture (Aalto et al., 1990). The coordination patterns of pistol motion and posture are more variable in the novice than in the skilled group (Ko et al., 2018). There are different quantitative and qualitative dynamics in pistol-aiming reflecting athlete's skill level with postural control foundation (Ko et al., 2018). The skill acquisition in pistol-aiming reduces the kinematic variables into a lower-dimensional functional unit over the posture and upper-limb system (Ko et al., 2017).

Vertical holding ability and cleanness of triggering are also important for shooting performance in the biathlon (Ihalainen et al., 2018). Postural stability in shooting direction is related to technical components of shooting, which indicates that athletes can reduce the aiming point movement in the holding and triggering phase by stabilizing their posture (Ihalainen et al., 2018). It seems that expert biathletes use a different strategy than expert rifle shooters, each of them adapting to the characteristics of their respective discipline (Larue et al., 1989).

The synchronization of bow and body sway plays a role in shot accuracy, which indicates that combined bow stability and balance exercises would contribute to better archery performance (Sarro et al., 2021). Reduced postural sway speed post-arrow release, greater bow draw force, and reduced clicker reaction time are predictors of higher scoring shots in elite recurve archers (Spratford and Campbell, 2017).

\section{Gymnastics}

Furthermore, specific postural stability control plays an essential role in acrobatic sports. Gymnastic experience during childhood is beneficial for the development of proprioceptive reweighting processes that lead to a more mature form of controlling and coordinating posture similar to adults (Busquets et al., 2021). Anthropometric characteristics and discipline-specific training experience are associated with postural steadiness (Opala-Berdzik et al., 2021). There is a relationship between anterior-posterior postural steadiness with eyes open and the artistic gymnasts' biological maturity, body mass, body height, greater age, and longer training experience (Opala-Berdzik et al., 2021). Overall postural steadiness regardless of visual conditions is associated with the acrobatic gymnasts' BMI percentiles and greater body mass (Opala-Berdzik et al., 2021).

The sport-specific task (i.e., single-leg back scale) is more sensitive in differentiating the level of expertise in young gymnasts than the simple task (i.e., bipedal standing) (Marcolin et al., 2019). While basic-level gymnasts have better postural stability in the bipedal standing, advanced-level gymnasts perform better in the single-leg back scale, particularly on balance time-dependent response to the rondade plus flicflac (Marcolin et al., 2019). In addition, experts have a more efficient perception of body orientation in space in skills that require a fine postural adjustment than controls (Bringoux et al., 2000). Increasing expertise through specific gymnastic training increases the relevance of interoceptive and/or otolithic inputs (Bringoux et al., 2000). There is an expert advantage on sway areas for dance-like but not static postural tasks (Munzert et al., 2019). Their advantage is task specific, which provides new insights into the specificity of postural performance in highly skilled athletes (Munzert et al., 2019). 
TABLE 1 | Neuromuscular control of postural stability and functional movement and/or athlete performance.

\begin{tabular}{|c|c|c|c|c|c|}
\hline Authors & Study design & Participants & Main variables & Main findings & $\begin{array}{l}\text { Postural stability control and } \\
\text { athlete performance }\end{array}$ \\
\hline
\end{tabular}

\section{Relationship between postural stability and functional movement and/or athletic performance}

\begin{tabular}{|c|c|c|}
\hline Ball et al., 2003 & $\begin{array}{l}20 \text { shots under } \\
\text { competition } \\
\text { conditions }\end{array}$ & 6 elite shooters \\
\hline Behm et al., 2005 & $\begin{array}{l}\text { Relationships } \\
\text { between hockey } \\
\text { skating speed and } \\
\text { specific } \\
\text { performance } \\
\text { measures }\end{array}$ & $\begin{array}{l}30 \text { competitive } \\
\text { junior and } \\
\text { secondary school } \\
\text { hockey players }\end{array}$ \\
\hline $\begin{array}{l}\text { Mononen et al., } \\
2007\end{array}$ & $\begin{array}{l}30 \text { shots in the } \\
\text { standing position at } \\
\text { a distance of } 10 \mathrm{~m} \\
\text { from the target }\end{array}$ & $\begin{array}{l}58 \text { right-hand male } \\
\text { conscripts from the } \\
\text { Finnish Air Force } \\
\text { Communications } \\
\text { School }\end{array}$ \\
\hline
\end{tabular}

AMTI LG6-4 force plate for Body sway is related to measuring body sway parameters;

SCATT shooting analysis system for measuring aim point fluctuation and shooting performance

Off-ice measures including squat jump, drop jump, a 40-yd sprint, 1 RM leg press, flexibility, and

balance ratio;

Electromyographic (EMG) activity of the dominant vastus lateralis and biceps femoris while skating, performing a change-of-direction drill, stopping, and turning Postural balance and rifle stability assessed in terms of anteroposterior and mediolateral sway velocity of the CoP movement, and horizontal and vertical deviation of the aiming point
Relationships between postural control variables and technical performance in different small-sided games (SSGs) - 1:1, 2:2 and $3: 3$
A simulated air rifle shooting competition series
16 trained male amateur soccer players
40 international- and national-level shooters
Measuring of postural sway in anterior-posterior and medial-lateral directions during one-legged and both-legged quiet-stance using a Tekscan HR Mat ${ }^{\mathrm{TM}}$
Optoelectronic device for measuring of shooting score and aiming point trajectory variables; Force platform for measuring of postural balance variables

performance in shooters; Body sway is related to aim point fluctuation in shooters; As body sway increases, performance decreases and aim point fluctuation increases for most relationships

There are significant correlations between sprint and balance tests and the skating performance;

There are significant correlations between balance and players under the age of 19 years but not those over 19 years old

Shooting accuracy is related to postural balance and rifle stability, but only at the inter-individual level;

There is a correlation between shooting score and behavioral performance variables; Postural balance is related to the shooting accuracy both directly and indirectly through rifle stability

There is a relationship between postural control and soccer-specific technical variables in 1:1,2:2 and 3:3 SSGS

Stability of hold, cleanness of triggering, timing of triggering and aiming accuracy are predictors of shooting performance, accounting for $81 \%$ of the variance in a shooting score; Direct effect of postural balance on performance is small, accounting for $<1 \%$ of the variance in a shooting score; Indirect effects could be greater through a more stable holding ability that correlate with postural balance
Body sway and aim point fluctuation are essential in elite rifle shooting; Highly individual-specific are performance errors

Significant correlations with balance suggest that stability may be associated with skating speed in younger players; Low correlations with drop jumps suggest that short contact time stretch-shortening activities is not an essential factor;

EMG activities illustrate very high activation levels associated with maximum skating speed

High postural balance and minimal movement of the gun barrel are essential determinants of successful shooting performance among novice shooters

Higher postural control levels are essential variables that affect success in technical skills under rival pressure and suddenly changing conditions

Aiming accuracy, cleanness of triggering, and timing of triggering contribute to shooting score in elite-level air rifle shooters 
TABLE 1 | Continued

\begin{tabular}{|c|c|c|c|c|}
\hline Authors & Study design & Participants & Main variables & Main findings \\
\hline $\begin{array}{l}\text { Ihalainen et al., } \\
2016 b\end{array}$ & $\begin{array}{l}\text { Simulated series of } \\
\text { air-rifle shooting- } \\
\text { competition in three } \\
\text { consecutive } \\
\text { seasons }\end{array}$ & 17 elite shooters & $\begin{array}{l}\text { Optoelectronic shooting } \\
\text { device for measuring of } \\
\text { shooting score and } \\
\text { aiming-point-trajectory } \\
\text { variables; } \\
\text { Force platform for } \\
\text { measuring of } \\
\text { postural-balance variables }\end{array}$ & $\begin{array}{l}\text { Seasonal mean test results in } \\
\text { stability of hold and cleanness } \\
\text { of triggering are related to } \\
\text { competition performances; } \\
\text { Changes in stability of hold and } \\
\text { cleanness of triggering are } \\
\text { related to changes in } \\
\text { performances; } \\
\text { Cleanness of triggering is } \\
\text { related to postural balance in } \\
\text { shooting direction, whereas } \\
\text { stability of hold is related to } \\
\text { balance in cross-shooting } \\
\text { direction }\end{array}$ \\
\hline $\begin{array}{l}\text { Verhoeven and } \\
\text { Newell, } 2016\end{array}$ & $\begin{array}{l}50 \text { basketball } \\
\text { free-throws with } \\
\text { both their dominant } \\
\text { and non-dominant } \\
\text { hand }\end{array}$ & $\begin{array}{l}25 \text { male college } \\
\text { students with a } \\
\text { range of skill levels }\end{array}$ & $\begin{array}{l}\text { The free-throw shot } \\
\text { recorded at } 120 \mathrm{~Hz} \text { through } \\
8 \text { VICON Bonita Optical } \\
\text { motion capture } \\
\text { cameras }\end{array}$ & $\begin{array}{l}\text { Trial-to-trial variance in release } \\
\text { parameters as well as postural } \\
\text { stability of the shooter, } \\
\text { synchronization of postural } \\
\text { movement and ball release are } \\
\text { strong predictors of } \\
\text { performance, with non-elite } \\
\text { shooters having a higher mean } \\
\text { and variability of CoM speed at } \\
\text { the time of ball release; } \\
\text { The synchronization between } \\
\text { the time of peak CoM and the } \\
\text { time of ball release increases as } \\
\text { a function of skill level and hand } \\
\text { dominance, with the better } \\
\text { performers releasing the ball } \\
\text { more closely to the time of CoM } \\
\text { peak height }\end{array}$ \\
\hline Edis et al., 2017 & $\begin{array}{l}\text { Relationships } \\
\text { between } \\
\text { parameters } \\
\text { designating } \\
\text { postural control }\end{array}$ & $\begin{array}{l}16 \text { youth soccer } \\
\text { players }\end{array}$ & $\begin{array}{l}\text { Measuring of postural sway } \\
\text { in anterior-posterior and } \\
\text { medial-lateral directions } \\
\text { during one and both leg } \\
\text { stance positions }\end{array}$ & $\begin{array}{l}\text { There is a significant } \\
\text { relationship between the } \\
\text { running speeds of 0-6, 6-10 } \\
\text { and } 10-16 \mathrm{~km} \cdot \mathrm{h}^{-1} \text { in } 2 \text { vs. } 2 \\
\text { and } 3 \text { vs. } 3 \text { games }\end{array}$ \\
\hline
\end{tabular}

Spratford and

Campbell, 2017

Ihalainen et al., 2018
39 recurve archers of an elite-level (23 male and 16 female) from four different countries prior to competition at a World Cup event levels and running

speeds in SSG

The effect of postural stability pre- and post-arrow release, arrow length, flight time, draw force and clicker reaction time on scoring outcomes and the performance

Factors determining 9 junior 8 national performance in team biathletes biathlon standing shooting at rest as well as after intense exercise
The CoP measurements $1 \mathrm{~s}$ prior to arrow release and 0.5 s post-arrow release using an AMTI force platform (1000 Hz); High-speed footage $(200 \mathrm{~Hz}$ ) for calculation of arrow flight time and flight score

40 resting shots (REST) and $2 \times 5$ shots simulating the competition (LOAD) after 5 min of roller skiing at 95\% of peak heart rate; Postural balance, aiming point trajectory and hit percentage measured from each shot
Maximum sway speed, draw force and clicker reaction time are variables that predict performance of the shot; Higher bow draw force, reduced clicker reaction time and postural sway speed post-arrow release are predictors of higher scoring shots

Cleanness of triggering (ATV) and vertical stability of hold (DevY) are the most important components affecting shooting performance both in REST and in LOAD;

Postural balance, especially in shooting direction, is related to DevY and ATV
Postural stability control and athlete performance

Stability of hold, cleanness of triggering, and postural balance affect performance in both training and competition situations in athletes at the elite level

The control of the trial-to-trial variability along the solution manifold of release parameters, as well as the coordination of postural control and ball release properties are important for shooting success changes as a function of skill level

Combining practices that are designed to train balance with football specific exercises in a single training session can significantly contribute to athlete performance

The clicker time, draw force and mainly maximum sway speed post-arrow release play an important role in the scoring outcomes in elite-level recurve archery

Cleanness of triggering and vertical holding ability are key factors in biathlon standing shooting performance; Postural balance especially in shooting direction is related to these shooting technical components;

Athletes may be able to reduce the movement of the aiming point in triggering phase and in the holding phase by improving their postural stability 
TABLE 1 | Continued

\begin{tabular}{|c|c|c|c|c|c|}
\hline Authors & Study design & Participants & Main variables & Main findings & $\begin{array}{l}\text { Postural stability control and } \\
\text { athlete performance }\end{array}$ \\
\hline $\begin{array}{l}\text { Caballero et al., } \\
2021\end{array}$ & $\begin{array}{l}\text { Relationships } \\
\text { between balance } \\
\text { and tennis } \\
\text { performance using } \\
\text { linear and } \\
\text { non-linear } \\
\text { parameters through } \\
\text { (1) the comparison } \\
\text { of tennis players of } \\
\text { different levels of } \\
\text { expertise and ages } \\
\text { and (2) the analysis } \\
\text { of the association } \\
\text { of balance and } \\
\text { tennis serving } \\
\text { speed and } \\
\text { accuracy }\end{array}$ & $\begin{array}{l}106 \text { recreational } \\
\text { and expert male } \\
\text { tennis players }\end{array}$ & $\begin{array}{l}\text { Temporal dynamics of } \\
\text { postural control during a } \\
\text { balance task on an } \\
\text { unstable surface analyzed } \\
\text { through the mean velocity } \\
\text { and the detrended } \\
\text { fluctuation analysis (DFAV) } \\
\text { of CoP }\end{array}$ & $\begin{array}{l}\text { Traditional variables measuring } \\
\text { balance performance only show } \\
\text { differences according to age } \\
\text { but not to sport performance; } \\
\text { CoP show a reduction of } \\
\text { auto-correlated variability with } \\
\text { age in expert players; } \\
\text { CoP dynamics is related to age } \\
\text { and discriminates sport } \\
\text { expertise }\end{array}$ & $\begin{array}{l}\text { Sport experience induces } \\
\text { balance adaptations that is } \\
\text { characterized by a higher ability } \\
\text { to perform postural } \\
\text { adjustments; } \\
\text { The lack of correlations } \\
\text { indicates that balance } \\
\text { measured with scattering } \\
\text { variables under non-specific } \\
\text { conditions is not a determinant } \\
\text { of tennis serve performance }\end{array}$ \\
\hline
\end{tabular}


TABLE 1 | Continued

\begin{tabular}{|c|c|c|c|c|}
\hline Authors & Study design & Participants & Main variables & Main findings \\
\hline Sarro et al., 2021 & $\begin{array}{l}\text { The relationship } \\
\text { between bow } \\
\text { stability and } \\
\text { postural control in } \\
\text { recurve archery } \\
\text { according to } \\
\text { shooting } \\
\text { performance }\end{array}$ & $\begin{array}{l}8 \text { archers who } \\
\text { participated in } \\
\text { national-level } \\
\text { competitions, and } \\
\text { trained four times a } \\
\text { week }\end{array}$ & $\begin{array}{l}6 \text { shot of arrows at a } \\
\text { 13-m distant target; } \\
\text { 3-dimensional position } \\
\text { of one marker attached } \\
\text { to the bow and the } \\
\text { CoP position of the } \\
\text { archer measured during } \\
\text { the aiming phase, } \\
\text { representing bow and } \\
\text { archer displacement, } \\
\text { respectively }\end{array}$ & $\begin{array}{l}\text { Length of the CoP trajectory } \\
\text { (DCoP), CoP displacement in the } \\
\text { direction across the target (CoPY), } \\
\text { and length of the bow trajectory } \\
\text { (Dbow) are higher in the lowest than } \\
\text { the highest scoring shot; } \\
\text { There is a significant correlation } \\
\text { between CoPX and vertical } \\
\text { displacement of the bow (DZ) } \\
\text { during the highest scoring shot, } \\
\text { and between CoP and bow } \\
\text { displacement in the direction } \\
\text { towards/away from the target } \\
\text { (CoPX and DX) }\end{array}$ \\
\hline
\end{tabular}

Effect of sport-specific training on functional movement and/or athletic performance

\begin{tabular}{|c|c|c|c|}
\hline Larue et al., 1989 & $\begin{array}{l}\text { The stability of } \\
\text { body-gun up to the } \\
\text { firing of a shot } \\
\text { when shooting in } \\
\text { standing position }\end{array}$ & $\begin{array}{l}2 \text { novices and } 2 \\
\text { experts in rifle } \\
\text { shooting, } 2 \text { novices } \\
\text { and } 2 \text { experts in } \\
\text { biathlon }\end{array}$ & $\begin{array}{l}\text { Electromyographic } \\
\text { activity of the tibialis } \\
\text { anterior, gastrocnemius } \\
\text { and deltoid muscles; } \\
\text { Rifle oscillation and } \\
\text { CoP displacements }\end{array}$ \\
\hline Aalto et al., 1990 & A simulated race & $\begin{array}{l}10 \text { competition } \\
\text { shooters }\end{array}$ & $\begin{array}{l}\text { Force platform for } \\
\text { measuring postural } \\
\text { stability with and } \\
\text { without competition } \\
\text { clothing }\end{array}$ \\
\hline
\end{tabular}

Era et al., $1996 \quad$ Posture control while aiming $7.5 \mathrm{~s}$ preceding the shot
National top-level, national and amateur rifle shooters
Bringoux et al., 2000

\begin{tabular}{|c|c|c|}
\hline $\begin{array}{l}\text { How motor skills } \\
\text { experts requiring a } \\
\text { good postural } \\
\text { control perceive } \\
\text { their body } \\
\text { orientation with few } \\
\text { gravity based } \\
\text { sensory cues }\end{array}$ & $\begin{array}{l}5 \text { expert gymnasts } \\
\text { ( } 4 \text { males and } 1 \\
\text { female) and } 5 \\
\text { non-gymnast } \\
\text { subjects ( } 3 \text { males } \\
\text { and } 2 \text { females) }\end{array}$ & $\begin{array}{l}\text { The body tilt when } \\
\text { pitching at } 0.05 \\
\text { deg.s }{ }^{-1} \text { in conditions } \\
\text { of body restriction } \\
\text { (strapped and body } \\
\text { cast altering the } \\
\text { somatosensory cues); } \\
\text { The Subjective Postural } \\
\text { Vertical (SPV) starting } \\
\text { from different angles of } \\
\text { pitch tilt }\end{array}$ \\
\hline
\end{tabular}

Expert biathletes use a different strategy than expert rifle shooters; No significant pattern emerges from tests with novice rifle shooters

Stability is significantly better in shooters than in untrained controls without supportive clothing; The Romberg quotient is higher in shooters than in controls, suggesting that they use an increased amount of vestibular and proprioceptive cues to stabilize their posture

Top-level male shooters stabilize their posture better than top-level female and national level male shooters, who are more stable than naive shooters;

Experienced shooters stabilize their posture better during the last seconds preceding the shot, whereas there are no differences when the successive windows are compared with each other in naive shooters;

Naive shooters have more pronounced CoF movement in the less successful trials; Not-efficient whole-body posture stabilization is not a reason for a poor result in top-level shooters There is a larger body tilt when totally restrained in the body cast in controls than in experts;

Controls exhibit significant errors of SPV judgmentwhereas the experts are very precise
Postural stability control and athlete performance

Synchronization between body and bow sway may influence the accuracy of the shot, suggesting that combined balance and bow stability training exercises would be beneficial to improve archery performance

Rifle shooters and biathletes adapt characteristics of their disciplines

Assiduous training aimed to improve balance contributes to good postural stability in shooters

Postural control is better in trained athletes who can improve their stability during the last seconds preceding the shot; A good body stabilization is the prerequisite for good shooting performance

More informative are

somatosensory than otolithic cues for the body orientation perception; The efficiency of otolithic and/or interoceptive inputs can be improved through a specific training to compensate for the lack of somatosensory cues 
TABLE 1 | Continued

\begin{tabular}{|c|c|c|c|c|c|}
\hline Authors & Study design & Participants & Main variables & Main findings & $\begin{array}{l}\text { Postural stability control and } \\
\text { athlete performance }\end{array}$ \\
\hline $\begin{array}{l}\text { Asseman et al., } \\
2004\end{array}$ & $\begin{array}{l}\text { Comparing the level } \\
\text { of performance and } \\
\text { postural control of } \\
\text { elite gymnasts in } \\
\text { postures } \\
\text { specifically trained } \\
\text { or not }\end{array}$ & 15 elite gymnasts & $\begin{array}{l}\text { Surface and mean } \\
\text { velocity of the CoP } \\
\text { motions }\end{array}$ & $\begin{array}{l}\text { The subject's level of postural } \\
\text { performance and control in one } \\
\text { condition is not correlated to the } \\
\text { corresponded level in another } \\
\text { condition; } \\
\text { Postural ability of elite gymnasts in } \\
\text { the handstand is not transferable to } \\
\text { upright standing postures }\end{array}$ & $\begin{array}{l}\text { Body movements and muscular } \\
\text { force regulation to maintain balance } \\
\text { are specific to the task } \\
\text { characteristics; } \\
\text { Postural performance and control in } \\
\text { gymnastics' skills are not } \\
\text { transferred or generalized to more } \\
\text { usual upright stances; } \\
\text { The level of athlete in this activity } \\
\text { does not implicate a corresponding } \\
\text { level in usual postures }\end{array}$ \\
\hline $\begin{array}{l}\text { Asseman et al., } \\
2008\end{array}$ & $\begin{array}{l}\text { A comparison of } \\
\text { body sway in } \\
\text { bipedal and } \\
\text { unipedal with eyes } \\
\text { open and eyes } \\
\text { closed }\end{array}$ & $\begin{array}{l}\text { Two groups of } 13 \\
\text { subjects: male elite } \\
\text { gymnasts of } \\
\text { international level } \\
\text { and portsmen of } \\
\text { regional level } \\
\text { involved in different } \\
\text { activities }\end{array}$ & $\begin{array}{l}\text { Center of gravity } \\
\text { motion computed from } \\
\text { CoP motion, estimating } \\
\text { postural control }\end{array}$ & $\begin{array}{l}\text { The two groups differ significantly in } \\
\text { the unipedal posture and with eyes } \\
\text { open; } \\
\text { Removal of vision affects similarly } \\
\text { both groups }\end{array}$ & $\begin{array}{l}\text { Gymnastics expertise improves } \\
\text { postural performances in situations } \\
\text { for which their practise is related to } \\
\text { (i.e., unipedal with eyes open) }\end{array}$ \\
\hline Croix et al., 2010 & $\begin{array}{l}\text { The effect of } \\
\text { somatosensory and } \\
\text { visual information } \\
\text { on handstand } \\
\text { performance; } \\
\text { The link of general } \\
\text { perceptual } \\
\text { characteristics of } \\
\text { gymnasts with their } \\
\text { handstand } \\
\text { performances }\end{array}$ & $\begin{array}{l}17 \text { gymnasts: an } \\
\text { expert group ( } 6 \\
\text { women and } 2 \\
\text { men), and } \\
\text { a non-expert group } \\
\text { ( } 7 \text { women and } 2 \\
\text { men) }\end{array}$ & $\begin{array}{l}\text { A handstand on a force } \\
\text { platform in } 4 \\
\text { conditions: open or } \\
\text { closed eyes on a firm or } \\
\text { foam support; } \\
\text { The surface area } \\
\text { covered by the CoP } \\
\text { trajectory }\end{array}$ & $\begin{array}{l}\text { Experts have significantly better } \\
\text { postural performance during the } \\
\text { handstand than nonexperts, } \\
\text { whatever the visual condition, } \\
\text { nonexperts are unable to maintain } \\
\text { the handstand without vision, } \\
\text { whatever the support, and the CoP } \\
\text { surface is significantly greater on } \\
\text { the foam surface than on the firm } \\
\text { surface for both experts and } \\
\text { nonexperts and, only for experts, } \\
\text { whatever the visual condition; } \\
\text { Experts are less field dependent } \\
\text { than nonexperts, and the } \\
\text { rod-and-frame test results are } \\
\text { positively correlated with postural } \\
\text { performance }\end{array}$ & $\begin{array}{l}\text { Expert gymnasts use the remaining } \\
\text { sensory modalities efficiently when } \\
\text { vision is removed; } \\
\text { Gymnastics training improves the } \\
\text { ability to change the frame of } \\
\text { reference }\end{array}$ \\
\hline $\begin{array}{l}\text { Omorczyk et al., } \\
2018\end{array}$ & $\begin{array}{l}\text { Relationships } \\
\text { between stability } \\
\text { indices registered in } \\
\text { two positions }\end{array}$ & $\begin{array}{l}46 \text { athletes }(23 \\
\text { juniors and } 23 \\
\text { seniors) practicing } \\
\text { gymnastics at } \\
\text { various levels of } \\
\text { advancement }\end{array}$ & $\begin{array}{l}\text { Standing and } \\
\text { handstand; } \\
\text { Posturograph CQ-Stab } \\
2 \mathrm{P}\end{array}$ & $\begin{array}{l}\text { CoP area, mean CoP amplitude, } \\
\text { mean CoP displacement of the } \\
\text { feet/hands in } M-L \text { direction and } \\
\text { maximal CoP displacement of the } \\
\text { feet/hands in } M-L \text { direction in both } \\
\text { standing position and handstand is } \\
\text { significantly lower in seniors; } \\
\text { The statokinesiogram path length, } \\
\text { both total and in A-P and } M-L \\
\text { directions in the standing position is } \\
\text { significantly lower in seniors }\end{array}$ & $\begin{array}{l}\text { Ability to control the position of the } \\
\text { body in both positions is better in } \\
\text { seniors than in juniors; } \\
\text { Stability variables in standing } \\
\text { position significantly correlate with } \\
\text { those in handstand in seniors but } \\
\text { not in juniors }\end{array}$ \\
\hline
\end{tabular}


TABLE 1 | Continued

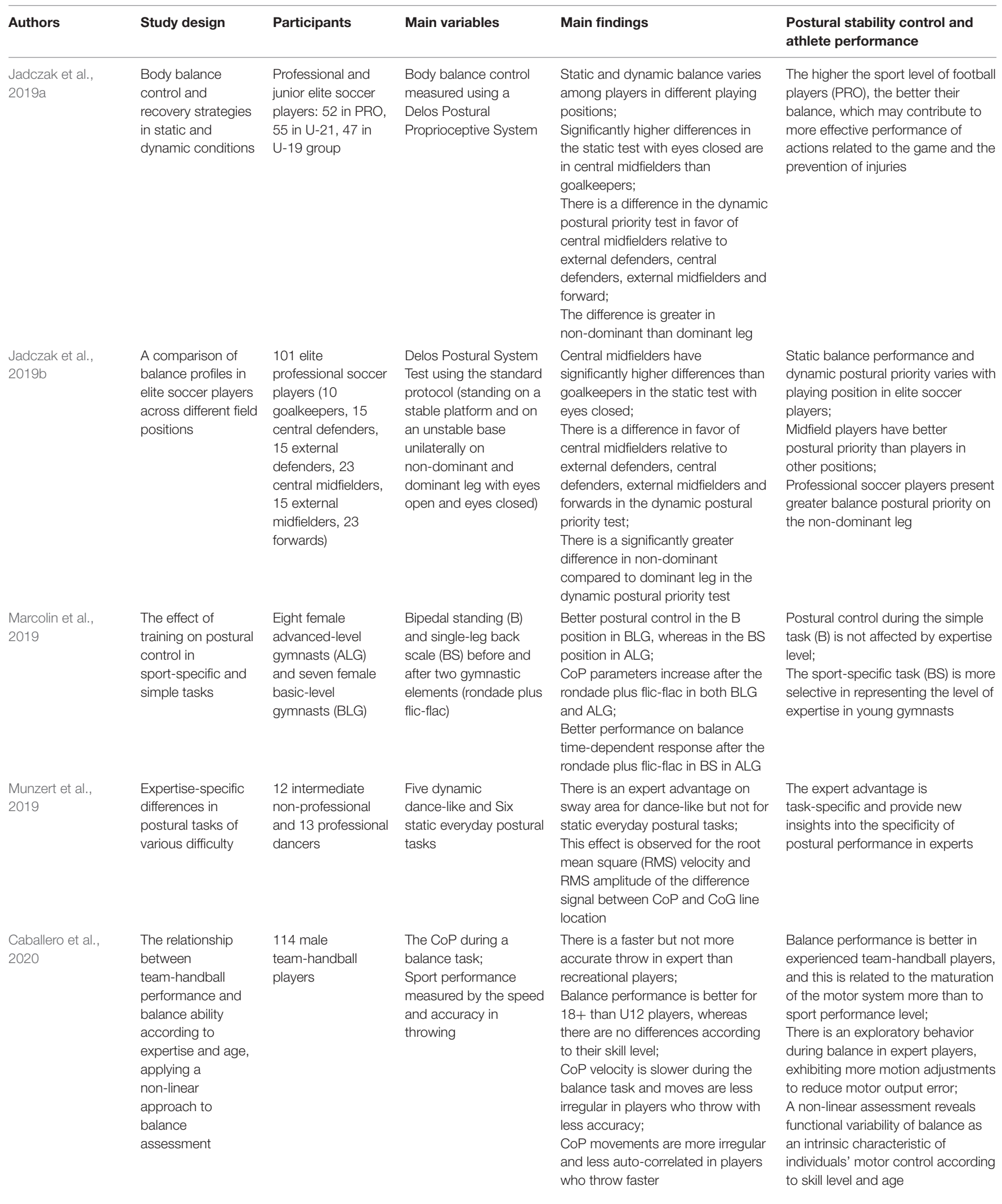


TABLE 1 | Continued

\begin{tabular}{|c|c|c|c|c|c|}
\hline Authors & Study design & Participants & Main variables & Main findings & $\begin{array}{l}\text { Postural stability control and } \\
\text { athlete performance }\end{array}$ \\
\hline $\begin{array}{l}\text { Andreeva et al., } \\
2021\end{array}$ & $\begin{array}{l}\text { Postural stability in } \\
\text { athletes of various } \\
\text { sports }\end{array}$ & $\begin{array}{l}936 \text { athletes of } \\
\text { different sports and } \\
\text { performance level }\end{array}$ & $\begin{array}{l}\text { The CoP sway area } \\
\text { (AS) and velocity (VCP) } \\
\text { during bipedal stance } \\
\text { with eyes open (EO) } \\
\text { and eyes closed (EC) } \\
\text { on a stabiloplatform } \\
(50 \mathrm{~Hz})\end{array}$ & $\begin{array}{l}\text { VCP-EO increases in shooters, } \\
\text { footbal players, boxers, } \\
\text { cross-country skiers, gymnasts, } \\
\text { runers, team sport players, } \\
\text { wrestlers, tennis players, alpine } \\
\text { skiers, rowers, speed skaters, and } \\
\text { figure skaters compared to controls }\end{array}$ & $\begin{array}{l}\text { Practicing sport is associated with } \\
\text { increased postural stability in } \\
\text { bipedal stance }\end{array}$ \\
\hline
\end{tabular}

Specific postural control in gymnasts' skills (i.e., postural ability in the handstand) is not transferred to basic upright stances (Asseman et al., 2004). Gymnastics expertise seems to improve postural performance only in conditions to which their practice is related (Asseman et al., 2008). There is lower frequency and variation of body sway in the handstand in more than less-experienced gymnasts (Sobera et al., 2019). While the first group concentrates on reducing anteriorposterior body sway with minimum medial-lateral movements, its values in a medial-lateral direction are irregular in the second group (Sobera et al., 2019). Postural performance in the handstand is significantly better in expert gymnasts than non-experts, whatever the visual condition (Croix et al., 2010). Experts are less field-dependent than non-experts, and this is positively correlated with postural performance (Croix et al., 2010). They use the remaining sensory modalities more efficiently under eyes closed conditions (Croix et al., 2010). The ability to change the frame of reference is improved through a high level of gymnastics training (Croix et al., 2010). Variables obtained in the handstand and standing position significantly correlate in the senior but not in the junior gymnasts (Omorczyk et al., 2018). Disabling visual control in the handstand and free-standing position in seniors deteriorates postural sway and increases CoP displacement in the anteroposterior and both directions. Lack of differences in $\mathrm{CoP}$ variables in the mediolateral direction in a freestanding position indicates that eye control is not important for body stability in the frontal plane in seniors practicing gymnastics $\mathrm{CoP}$ movement control in the mediolateral direction (Puszczałowska-Lizis and Omorczyk, 2019).

\section{Team Sports}

Postural stability control is also important for performance in team sports and may vary among athletes of different competition levels. Both dynamic and static tests should be used for the assessment of balance as postural control performance in these two cases is not related (Pau et al., 2015). For instance, the measures from the Star Excursion Balance Test may not reflect the balance performance in well-trained athletes (i.e., professional basketball and football players) who have a better balance when performing sportrelated skills (Halabchi et al., 2020). However, this test includes static postures, which may better reflect postural deficits in more experienced athletes than dynamic tests (Halabchi et al., 2020).
The hockey skating performance significantly correlates with balance and sprint tests, which demonstrates the important role postural stability plays in skating speed in young players (Behm et al., 2005). Improving postural control by decreasing CoM speed at ball release is important for a higher level of shooting in basketball (Verhoeven and Newell, 2016). Incorporating postural control in the free throw shot is a critical qualitative change in coordination resulting from practice (Verhoeven and Newell, 2016). Also, volleyball players may develop a unique postural control (Borzucka et al., 2020b). Their sensory resources should be optimally distributed between sport-specific skills on the court and postural control (Borzucka et al., 2020b). They use diversified postural strategies for the maintenance of balance whereby reducing the contribution of proprioception for more challenging posture-motor tasks (Borzucka et al., 2020a). A different model of sensory integration is used by volleyball players for postural control compared to non-athletes, which may be explained by their better "dynamic" visual acuity (Agostini et al., 2013). Dynamic balance is better in professional than collegiate and high school baseball players (Butler et al., 2016).

Soccer players have superior postural control when compared to those involved in contact sport and no sport at all (Liang et al., 2019). Contact sports increase postural control through increased use of vestibular and proprioceptive information (Liang et al., 2019). Players with soccer-specific training improve executive control and proprioceptive functions, which results in better single-support balance during a dynamic visuomotor lower limbreaching task (Snyder and Cinelli, 2020).

The contribution of vision in the maintenance of balance is less important in the professional national-level than amateur regional-level soccer players (Ben Moussa et al., 2012). Balance performance in terms of more efficient and faster stabilization after a forward jump is better in young national-level soccer players, whereas a one-leg static standing test is not sensitive enough to reveal differences in postural control associated with the combination of physical and technical features (Pau et al., 2018). Stabilometric variables improve with age until maturity (Zago et al., 2020). The higher the sport level of football players, the better their balance (Jadczak et al., 2019a). Greater balance in professional soccer players is on the non-dominant leg (Jadczak et al., 2019b). Static balance in elite soccer players varies across playing positions with better postural control in midfield players than those in other positions (Jadczak et al., 2019b). The level of playing experience influences postural control in test conditions specific to playing 
soccer (Paillard et al., 2006). Postural regulation changes from visual to vestibular and proprioceptive contribution, which allows better visual control of game situations in the field (Paillard et al., 2006).

Experienced team-handball players exhibit better balance performance, which is more associated with the maturation of the motor system than their performance level (Caballero et al., 2020). It seems that players with a higher level of expertise exhibit a better ability to perform motion adjustments to reduce motor output error (Caballero et al., 2020). Although postural adjustments during a balance task have a differential feature in expert players, this ability is not crucial for a tennis serve performance (Caballero et al., 2021). However, this does not reject the association of balance with other tennis drills such as pivoting maneuvers, sudden decelerations, and fast cutting maneuvers (Caballero et al., 2021).

\section{Other Sports}

Furthermore, balance, core strength and stability, flexibility, and peripheral muscle strength are associated with golf performance (Wells et al., 2009). Using concurrent mental tasks, differences in balance performance between expert surfers and controls can be found, whereas standard balance tests may not be able to elucidate whether surfing expertise facilitates balance adaptations (Chapman et al., 2008). When sharing attention with a concurrent mental task, sway path length increases in expert surfers compared to controls (Chapman et al., 2008). A different model of sensory integration was found in young kayaking and canoeing athletes than in non-athletes, which may be ascribed to a subtle re-adaptation deficit after disembarking to a stable surface with diminished sensitivity of vestibular apparatus and vision (Stambolieva et al., 2012). Better postural stability is also present in pentathletes who are less vision-dependent than untrained individuals. Conscious control of body alignment and a high level of concentration are the main factors responsible for minimizing body oscillations in pentathletes (Sadowska et al., 2019). Horseback riding may develop better postural muscle tone and particular proprioceptive abilities on standing posture during bipedal dynamic perturbations (Olivier et al., 2019). Interestingly, less anteroposterior movement during chair rising was found in master runners compared with young athletes, suggesting that they are not spared from the age-associated decline in postural stability and may benefit from specific balance training (Leightley et al., 2017).

However, some studies found no significant relationship between postural balance control and athlete performance. For instance, both the isokinetic core power and a onelegged static balance do not correlate with overall World Cup points in competitive snowboarders (Platzer et al., 2009b). Furthermore, unilateral stance with eyes closed demonstrates a positive correlation with pitch velocity, whereas there is no significant correlation between unilateral stance with eyes open or eyes closed and pitching error in college baseball pitchers (Marsh et al., 2004). Similarly, there is a lack of correlation between balance, measured with scattering variables in a non-specific task, and tennis serving speed and accuracy (Caballero et al., 2021). Furthermore, balance is not associated with team-handball performance (Caballero et al., 2020). Although the accuracy of the throws revealed a slight positive correlation with mean CoP velocity magnitude (players with better throw accuracy moved faster during the balance task), there was a negative correlation between the ball speed and bivariate variable error in experts (Caballero et al., 2020). Nevertheless, low-to-moderate correlations between unipedal balance ability and the players' technical level suggest that some technical soccer skills improve more after balance than typical soccer training (Cè et al., 2018). This discrepancy in findings may be mainly ascribed to the degree of physical development of a particular group of athletes or their exposure to sport-specific tasks. Also, a variety of methods used for balance assessment may play a role in a weak relationship between postural stability and functional movement or athlete performance. While static balance tests may be suitable for shooters, biathletes, or archers, for athletes of freestyle sports, snowboarding, skateboarding, windsurfing, or cycle acrobacy, the dynamic balance tests may represent a more appropriate alternative. Additionally, measurement of $\mathrm{CoP}$ variables using laboratory diagnostic systems may not be specific enough for most athletes, namely, those at a high level of competition. Moreover, postural stability may not be a key factor of athletic performance, for instance, a tennis serve or the accuracy and speed in throwing.

\section{The Role of Neuromuscular Control of Core Stability in Functional Movement and/or Athlete Performance}

Analysis of the literature revealed (Table 2) that out of 13 selected studies, seven (54\%) investigated the relationship between core (trunk) stability-related variables and functional movement and/or athletic performance (Abt et al., 2007; Nesser et al., 2008; Nesser and Lee, 2009; Chaudhari et al., 2011; Ozmen, 2016; Anand et al., 2017; de Bruin et al., 2021). Three of them (43\%) included only variables of athletic performance (Chaudhari et al., 2011; Anand et al., 2017; de Bruin et al., 2021), another three studies (43\%) incorporated variables of functional movement and athletic performance (Nesser et al., 2008; Nesser and Lee, 2009; Ozmen, 2016), and one study (14\%) focused on changes in the functional movement resulting from compromised core stability (Abt et al., 2007).

The remaining six studies (46\%) evaluated the effects of various core or neuromuscular training programs on core stability, functional movement, and athletic performance (Stanton et al., 2004; Saeterbakken et al., 2011; Sannicandro and Cofano, 2017; Vitale et al., 2018; Kuhn et al., 2019; Felion and DeBeliso, 2020). Three of them (50\%) investigated the effects of core stabilization exercises on functional movement and performance variables, strength, or core stability (Stanton et al., 2004; Sannicandro and Cofano, 2017; Kuhn et al., 2019). Two studies (33\%) examined the effects of core stabilization exercises only on variables of athletic performance (Saeterbakken et al., 2011; Felion and DeBeliso, 2020). One study (17\%) evaluated 
TABLE 2 | Neuromuscular control of core stability and functional movement and/or athlete performance.

\begin{tabular}{|c|c|c|c|c|c|}
\hline Authors & Study design & Participants & Methodology/Main variables & Outcomes & Main findings \\
\hline \multicolumn{6}{|c|}{ Relationship between core stability and functional movement and/or athletic performance } \\
\hline Abt et al., 2007 & $\begin{array}{l}\text { Changes in } \\
\text { pedaling forces and } \\
\text { lower extremity joint } \\
\text { kinematics as a } \\
\text { result of } \\
\text { compromised core } \\
\text { stability }\end{array}$ & $\begin{array}{l}15 \text { cyclists, } \\
\text { members of local } \\
\text { road cycling team }\end{array}$ & $\begin{array}{l}\text { 3D Motion Analysis System, } \\
\text { dependent kinematic variables: } \\
\text { total frontal and sagittal plane } \\
\text { motion of the hip and knee and } \\
\text { total sagittal plane motion of } \\
\text { the ankle; } \\
\text { Core fatigue: Isokinetic Torso } \\
\text { Rotation Test: Biodex System } 3 \\
\text { Multi-Joint Testing and }\end{array}$ & $\begin{array}{l}\text { After the core fatigue workout: } \\
\text { significant decrease } \\
(30.0-43.3 \%) \text { in peak torque, } \\
\text { total work, average power, } \\
\text { maximal repetition total work, } \\
\text { and average peak torque; } \\
\text { an increase in total frontal plane } \\
\text { knee motion and total sagittal } \\
\text { plane knee and ankle motion }\end{array}$ & $\begin{array}{l}\text { Core fatigue results in altered } \\
\text { cycling mechanics that could } \\
\text { increase the risk of knee injury; } \\
\text { Improved core stability and } \\
\text { endurance could promote } \\
\text { greater alignment of the lower } \\
\text { extremity when riding for } \\
\text { extended duration as the core } \\
\text { is more resistant to fatigue }\end{array}$ \\
\hline
\end{tabular}

Nesser et al., 2008 The relationships

Nesser and Lee, 2009

Chaudhari et al., 2011

$\begin{array}{ll}\text { Ozmen, } 2016 \quad & \text { The relationships } \\ \text { between core } & \text { stability, jumping } \\ \text { performance and } \\ \text { dynamic balance }\end{array}$

Anand et al., 2017 The relationship between bowling speed in cricket and core stability and pitching between core stability and various strength and power variables in strength and power athletes

29 male football players of the National Collegiate Athletic Association Division I

The relationship between core stability and various strength and power variables

The relationship between lumbopelvic control performance
16 National Collegiate Athletic Association Division I female football players trained specifically for strength and power

48 pitchers who pitched 50 or more innings in Minor League competition of $A, A A$, or $A A A$ levels

17 male soccer players

82 cricket medium and medium fast bowlers of district and universities
Core stability: plank test (prone plank, left side plank and right side plank);

Bowling speed: BUSHNELL Velocity Speed Gun 
TABLE 2 | Continued

\begin{tabular}{|c|c|c|c|c|c|}
\hline Authors & Study design & Participants & $\begin{array}{l}\text { Methodology / Main } \\
\text { variables }\end{array}$ & Outcomes & Main findings \\
\hline $\begin{array}{l}\text { de Bruin et al., } \\
2021\end{array}$ & $\begin{array}{l}\text { The relationship } \\
\text { between athletic } \\
\text { performance and } \\
\text { core stability }\end{array}$ & $\begin{array}{l}83 \text { female athletes } \\
\text { from the university } \\
\text { teams: hockey } \\
(n=24), \text { netball } \\
(n=16), \text { running } \\
(n=11), \text { soccer } \\
(n=15), \text { and tennis } \\
(n=17)\end{array}$ & $\begin{array}{l}\text { Core strength and endurance: } \\
\text { Biering-Sørensen tests - } \\
\text { isometric back extension (IBE), } \\
\text { lateral flexion (LF) and } \\
\text { abdominal flexion (AF); } \\
\text { Core neuromuscular control } \\
\text { (NMC): Welch Allyn FlexiPort } \\
\text { pressure biofeedback unit; } \\
\text { Athletic performance: T-test, } 40 \\
\text { m sprint, medicine ball chest } \\
\text { throw (MBCT) and vertical jump } \\
\text { (VJ) }\end{array}$ & $\begin{array}{l}\text { Most weak correlations in all } \\
\text { sports ( } r=0.10-0.39) \text {; } \\
\text { Very strong correlation between } \\
\text { VJ and LF ( } r=0.90) \text {; } \\
\text { Moderate correlations in all } \\
\text { sports between core strength, } \\
\text { endurance and motor control } \\
\text { and certain athletic } \\
\text { performance tests } \\
(r=0.40-0.69)\end{array}$ & $\begin{array}{l}\text { Correlations between core } \\
\text { stability and athletic } \\
\text { performance are negligible or } \\
\text { weak; } \\
\text { Athletic performance in different } \\
\text { sports is associated with } \\
\text { different components of core } \\
\text { stability }\end{array}$ \\
\hline \multicolumn{6}{|c|}{ Effect of core stability training on functional movement and/or athletic performance } \\
\hline Stanton et al., 2004 & $\begin{array}{l}\text { The effect of short } \\
\text { term Swiss ball } \\
\text { training (SBT) on } \\
\text { core stability and } \\
\text { running economy }\end{array}$ & $\begin{array}{l}18 \text { male athletes } \\
\text { from Basketball } \\
\text { and Touch Football } \\
\text { School of } \\
\text { Excellence in Sport } \\
\text { program: EG } \\
(n=8), C G(n=10)\end{array}$ & $\begin{array}{l}\text { SBT sessions } 6 \text { weeks, two } \\
\text { times a week, approximately } \\
25 \text { min. during regular training, } \\
\text { supervised by researcher; } \\
\text { Core stability: } 5 \text { level Sahrmann } \\
\text { core stability test with Stabilizer } \\
\text { Pressure Biofeedback Unit; } \\
\text { Maximal aerobic power } \\
\left(\mathrm{VO}_{2} \text { max) and running }\right. \\
\text { economy (RE): incremental } \\
\text { treadmill running test to } \\
\text { volitional exhaustion }\end{array}$ & $\begin{array}{l}\text { Significant effect of SBT on } \\
\text { core stability in the EG; } \\
\text { No significant differences in } \\
\text { myoelectric activity of } \\
\text { abdominal and back muscles, } \\
\text { treadmill } \mathrm{VO}_{2} \text { max, } \mathrm{RE} \text {, or } \\
\text { running posture in both } \mathrm{EG} \text { and } \\
\mathrm{CG}\end{array}$ & $\begin{array}{l}\text { SBT has positive effect on core } \\
\text { stability without improvements } \\
\text { of physical performance }\end{array}$ \\
\hline $\begin{array}{l}\text { Saeterbakken } \\
\text { et al., } 2011\end{array}$ & $\begin{array}{l}\text { The effect of core } \\
\text { stabilization training } \\
\text { (CST) on maximal } \\
\text { throwing velocity }\end{array}$ & $\begin{array}{l}24 \text { female } \\
\text { high-school } \\
\text { handball players } \\
\text { randomly divided } \\
\text { into a CST ( } n=14) \\
\text { and a control group } \\
\text { (CG, } n=10)\end{array}$ & $\begin{array}{l}\text { 6-week regular handball } \\
\text { training in both groups; } \\
\text { Additional progressive core } \\
\text { stability training program in the } \\
\text { CST group (twice a week for } \\
75 \text {-min, } 6 \text { unstable closed } \\
\text { kinetic chain exercises); } \\
\text { Throwing velocity: } 2 \text { photocell } \\
\text { arrays with an accuracy } \\
\text { of } \pm 0.001 \mathrm{~s}\end{array}$ & $\begin{array}{l}\text { There is a significant increase of } \\
\text { maximal throwing velocity in the } \\
\text { CST group (4.9\%) but not in the } \\
\text { CG }\end{array}$ & $\begin{array}{l}\text { CST using unstable, closed } \\
\text { kinetic chain movements } \\
\text { improves maximal throwing } \\
\text { velocity; } \\
\text { Stronger and more stable } \\
\text { lumbopelvic hip complex may } \\
\text { contribute to higher rotational } \\
\text { velocity in multisegmental } \\
\text { movements }\end{array}$ \\
\hline Vitale et al., 2018 & $\begin{array}{l}\text { The effects of } \\
\text { neuromuscular } \\
\text { training program on } \\
\text { dynamic balance } \\
\text { and vertical jump } \\
\text { performance }\end{array}$ & $\begin{array}{l}24 \text { elite junior male } \\
\text { skiers randomized } \\
\text { in an experimental } \\
\text { group }(E G, n=12) \\
\text { and a control group } \\
(\mathrm{CG}, n=12)\end{array}$ & $\begin{array}{l}\text { 8-week training program (16 } \\
\text { sessions, } 3 \text { phases); partly } \\
\text { different exercises on core } \\
\text { stability, body-weight } \\
\text { strengthening and plyometric } \\
\text { exercises on dynamic postural } \\
\text { control and vertical jump } \\
\text { performance in each phase; } \\
\text { circuit training form during } \\
\text { warming up (30 min); } \\
\text { Dynamic balance: lower quarter } \\
\text { Y-Balance test (YBT) with } \\
\text { standardized testing protocol; } \\
\text { Jumping performance: } \\
\text { countermovement (CMJ) and } \\
\text { drop jump (DJ) on Optojump } \\
\text { Next }\end{array}$ & $\begin{array}{l}\text { Positive effects on pre to post } \\
\text { measures in anterior, } \\
\text { postero-medial, postero-lateral } \\
\text { directions, and composite YBT } \\
\text { score for both lower limbs in } \\
\text { the EG; } \\
\text { No significant changes in the } \\
\text { CG; } \\
\text { No significant changes in CMJ } \\
\text { and DJ in both EG and CG }\end{array}$ & $\begin{array}{l}\text { There is a positive effect of } \\
\text { neuromuscular training on } \\
\text { dynamic balance ability but not } \\
\text { on vertical jump performance; } \\
\text { It may be effective in increasing } \\
\text { lower limb joint awareness and } \\
\text { postural control }\end{array}$ \\
\hline
\end{tabular}


TABLE 2 | Continued

\begin{tabular}{|c|c|c|c|c|c|}
\hline Authors & Study design & Participants & $\begin{array}{l}\text { Methodology / Main } \\
\text { variables }\end{array}$ & Outcomes & Main findings \\
\hline Kuhn et al., 2019 & $\begin{array}{l}\text { The effects of core } \\
\text { stabilization training } \\
\text { (CST) on maximal } \\
\text { throwing velocity } \\
\text { and core strength } \\
\text { parameters }\end{array}$ & $\begin{array}{l}20 \text { female handball } \\
\text { players from } \\
\text { German non-elite } \\
\text { handball squad }\end{array}$ & $\begin{array}{l}\text { 6-week CST (twice a week for } \\
45 \text { min., } 9 \text { specific core and } \\
\text { rotational exercises for ventral, } \\
\text { dorsal and lateral core muscles } \\
\text { chain on an unstable surface); } \\
\text { Maximum voluntary isometric } \\
\text { strength (MIS) of the trunk } \\
\text { using isometric dynamometer } \\
\text { Beck-check 607; } \\
\text { Endurance strength of ventral, } \\
\text { dorsal and lateral core chains } \\
\text { using a Swiss Olympic Medical } \\
\text { Center core performance test } \\
\text { battery; } \\
\text { Throwing velocity using } \\
\text { OPTOJump Next }\end{array}$ & $\begin{array}{l}\text { A significant improvement in } \\
\text { MIS of left lateral core muscle } \\
\text { chain in the EGcompared to the } \\
\text { CG; } \\
\text { A significant improvement in } \\
\text { MIS of ventral core endurance } \\
\text { (35\%) and the lateral right core } \\
\text { muscles ( } 21 \% \text { ) in the EG; } \\
\text { A significant increase in } \\
\text { throwing velocity of jump throw } \\
\text { in both EG (12\%) and CG ( } 8 \%) \\
\text { but not velocity of standing } \\
\text { throw }\end{array}$ & $\begin{array}{l}\text { CST effectively increases } \\
\text { isometric strength and } \\
\text { endurance of core muscles but } \\
\text { does not enhance throwing } \\
\text { velocity when compared to } \\
\text { standard training }\end{array}$ \\
\hline $\begin{array}{l}\text { Felion and } \\
\text { DeBeliso, } 2020\end{array}$ & $\begin{array}{l}\text { The effect of core } \\
\text { training }(\mathrm{CT}) \\
\text { program on force } \\
\text { production in } \\
\text { torsional } \\
\text { movements }\end{array}$ & $\begin{array}{l}\text { Students, members } \\
\text { of baseball team at } \\
\text { Granger HS, UT, } \\
\text { United States }\end{array}$ & $\begin{array}{l}\text { Experimental group (EG): } \\
6 \text {-week CT program (twice a } \\
\text { week, } 1 \mathrm{~h} \text { /day), in addition to } \\
\text { specific training; Control group } \\
\text { (CG): } 6 \text {-week baseball specific } \\
\text { training only (twice a week, } \\
2 \mathrm{~h} / \text { day). } \\
\text { Throwing velocity (TV) and } \\
\text { ball-exit velocity (BEV) using } \\
\text { Stalker Sport II radar gun; BEV: } \\
\text { speed of the ball immediately } \\
\text { after being struck by the } \\
\text { baseball bat }\end{array}$ & $\begin{array}{l}\text { Neither EG nor CG increase in } \\
\text { TV following the 6-week CT } \\
\text { intervention; } \\
\text { A significant increase in BEV in } \\
\text { the EG but not in the CG }\end{array}$ & $\begin{array}{l}\text { Implementing of CT with } \\
\text { additional rotational exercises } \\
\text { with free weights, resistance } \\
\text { bands, or medicine balls leads } \\
\text { to additional gains in torso } \\
\text { rotational strength and } \\
\text { potentially improvement in BEV }\end{array}$ \\
\hline
\end{tabular}

the effect of neuromuscular training on selected parameters of functional movement (Vitale et al., 2018).

Regarding the sport, eleven studies (85\%) were conducted in team sports, such as baseball, basketball, cricket, football, handball, soccer, and touch ball (Stanton et al., 2004; Nesser et al., 2008; Nesser and Lee, 2009; Chaudhari et al., 2011; Saeterbakken et al., 2011; Ozmen, 2016; Anand et al., 2017; Sannicandro and Cofano, 2017; Kuhn et al., 2019; Felion and DeBeliso, 2020; de Bruin et al., 2021) and two studies (15\%) were carried out in individual sports, such as cycling and skiing (Abt et al., 2007; Vitale et al., 2018).

\section{The Relationship Between Core Stability and Functional Movement and/or Athletic Performance}

Among seven studies, six investigated the association of core stability with variables of athletic performance (Chaudhari et al., 2011; Anand et al., 2017; de Bruin et al., 2021) or both functional movement and athletic performance (Nesser et al., 2008; Nesser and Lee, 2009; Ozmen, 2016), whereas one study dealt with changes in functional movement resulting from compromised core stability (Abt et al., 2007).

The most investigated characteristics of core stability (Nesser et al., 2008; Nesser and Lee, 2009; Ozmen, 2016; Anand et al., 2017) were core or lumbopelvic neuromuscular control (Chaudhari et al., 2011; de Bruin et al., 2021), and core strength and endurance (Abt et al., 2007; de Bruin et al., 2021). Among functional movement characteristics, it was the kinematics of movement (Abt et al., 2007) and jumping abilities that stood out (Ozmen, 2016; de Bruin et al., 2021), whereas factors of athletic performance included ball speed (Anand et al., 2017), running speed, agility, and explosiveness of upper body (de Bruin et al., 2021). All studies dealing with the association of core stability with functional movement and athletic performance used a crosssectional design. In all seven studies, only one selected group of athletes of a certain type of sport was tested.

Regarding the methodology of core stability characteristics, the following tests were used: trunk flexion, back extension, left and right bridge (Nesser et al., 2008; Nesser and Lee, 2009), core stability McGills protocol (Ozmen, 2016), prone plank, left and right side plank (Anand et al., 2017), and BieringSørensen test (de Bruin et al., 2021). The "Level belt" was used for the lumbopelvic control (Chaudhari et al., 2011), isokinetic torso rotation test on a Biodex system and 32 min circuit of exercises targeting the core muscles evaluated core muscle fatigue (Abt et al., 2007), and biofeedback unit was applied for the core neuromuscular control (Ozmen, 2016). Regarding the functional movement characteristics, three-dimensional motion analysis (Abt et al., 2007) and star excursion balance test for dynamic balance (Ozmen, 2016) were used. Athletic performance characteristics were evaluated using the radar speed gun (Anand et al., 2017), 20-m run, 40-m run, $T$-test, agility test, shuttle run, medicine ball throw (Nesser et al., 2008; Nesser and Lee, 2009; de Bruin et al., 2021), squat jump (Ozmen, 2016), and the number of innings pitched during a season (Chaudhari et al., 2011). 
Core stability provides a foundation for force production in the lower and upper limbs (Willardson, 2007). This is a requisite for optimal functional movement and consequently also for better athletic performance (Abt et al., 2007; Chaudhari et al., 2011; Anand et al., 2017). However, some studies do not find this link between core functions and the movement of lower and upper limbs. In general, two research approaches exist that examine the association of core stability (lumbopelvic control) with functional movement and athletic performance. Some studies examined the importance of core stability or lumbopelvic control using strength, endurance, agility, speed, or other physical abilities tests as surrogate measures of functional movement and athletic performance (Nesser et al., 2008; Nesser and Lee, 2009; Ozmen, 2016; de Bruin et al., 2021). It has been proposed that well-trained athletes have general level of abilities, such as agility, explosive power, and speed, in addition to core stability, regardless of the specificity of the sport, and that there is a relationship between them. Other studies used direct measures of functional movement or athletic performance (Abt et al., 2007; Chaudhari et al., 2011; Anand et al., 2017). For instance, investigating the relationship between cycling mechanics and core stability revealed that improved core stability and endurance could promote greater alignment of the lower extremity when riding for extended durations as the core is more resistant to fatigue (Abt et al., 2007). Lumbopelvic control influences overall performance for baseball pitchers, thus a simple test of lumbopelvic control can potentially identify individuals who have a better chance of pitching success (Chaudhari et al., 2011). Throwing accuracy is significantly better in cricket bowlers with well-developed than poorly developed core stability (Anand et al., 2017).

The association of core stability with some variables of athletic performance in sports such as hockey, netball, tennis, soccer, and running supports the fact that its significance regarding some motor abilities in particular sports partly differs. However, when these sports were analyzed separately, there were similar moderate correlations between core strength or endurance and motor abilities in the tests used (de Bruin et al., 2021). There were strong correlations between abdominal flexion endurance and the vertical jump in runners, and between isometric back extension strength and the sprint in tennis players. However, the core strength and/or stability does not correlate with the strength and performance measures (10 yard shuttle run, 40 yard sprint, countermovement jump, 1RM squat, 1RM bench press) in athletes who train for strength and football skills. Despite these non-significant correlations, it is not reasonable to neglect the core. Nonetheless, it seems that the core musculature is no more important than any other part of the body (Nesser and Lee, 2009).

A belief that core stability is important for strength and power production in sport was not corroborated in male football players. The core stability was significantly but not strongly correlated with power and strength variables (10-yd shuttle run, 20- and 40-yd sprints, countermovement jump, 1RM squat, $1 \mathrm{RM}$ bench press, 1RM power clean). Correlations between core stability and strength or power, and sprints or shuttle run were moderate to weak but significant. This indicates that core strength contributes to power and strength performance and therefore should be taken into account (Nesser et al., 2008). However, there was a negative correlation between the jump height and trunk flexion, and no significant association was found between the jump height and side-bridge trunk extension in male soccer players. Similarly, the relationship between core stability and dynamic balance was not significant (Ozmen, 2016). These findings indicate that an understanding of the role of core stability in body movements most likely requires testing under sportspecific conditions. All of the athletic performance measures were mainly one repetition of explosive movements or sprints lasting a few seconds. The core stability was evaluated using isometric muscle contractions or muscle endurance tests. However, the core stability and performance of these two variables should not be compared. While sub-maximal muscle contractions, activation of more slow-twitch muscle fibers, and anaerobic glycolysis are typical for most core stability tests, the agility, power, strength, and running tests involve primarily maximum force production, activation of fast twitch muscle fibers, and the ATP-CP energy system (Nesser et al., 2008; Nesser and Lee, 2009; de Bruin et al., 2021).

The second type of study represents relationships between core stability and bowling speed in cricket, walks, hits per innings pitched and total innings pitched in baseball and functional movement in cycling. Cricket players with welldeveloped stability of the core manifest high quality in the kinetic chain of movements when bowling that probably results in increased bowling speed. They can better control their trunk position and motion over the pelvis and leg. This allows optimum generation and transfer of force to the terminal segment in the kinetic chain of specific movements. Core stability provides integration of proximal and distal segments in increasing bowling speed (Anand et al., 2017). Lumbopelvic control is related to performance in baseball pitchers (Chaudhari et al., 2011). The study revealed differences between lumbopelvic control and walks plus hits per innings pitched and total innings pitched. Significantly lower walks plus hits per innings pitched were found in the group with better than those with poorer lumbopelvic control. Furthermore, core stability also plays a role in the functional movement in cycling. For instance, lower extremity cycling mechanics is influenced by the core fatigue workout. Several kinematic variables were altered whereas work variables and the pedal force remained unchanged (Abt et al., 2007).

\section{Core Stability Training and Functional Movement and/or Athletic Performance}

Training programs were usually aimed at the increase of athletic performance factors (Saeterbakken et al., 2011; Kuhn et al., 2019) or variables of functional movement (Stanton et al., 2004; Sannicandro and Cofano, 2017; Vitale et al., 2018; Felion and DeBeliso, 2020) and were often combined with the development of core stability and strength (Stanton et al., 2004; Kuhn et al., 2019; Felion and DeBeliso, 2020) or the dynamic balance (Vitale et al., 2018).

The duration of intervention was from 4 to 6 weeks (Stanton et al., 2004; Saeterbakken et al., 2011; Sannicandro and Cofano, 2017; Kuhn et al., 2019; Felion and DeBeliso, 2020) or 8 weeks 
(Vitale et al., 2018), two times per week with a duration of 25-45 min (Stanton et al., 2004; Sannicandro and Cofano, 2017; Vitale et al., 2018; Kuhn et al., 2019) to 60-75 min (Saeterbakken et al., 2011; Felion and DeBeliso, 2020). While the 25-30 min programs were a part of warming up, the 45-75 min programs were organized apart from standard training. Core stabilization training programs were supervised by coaches, conditioning specialists, or researchers.

Core stabilization training programs included core exercises (Stanton et al., 2004; Saeterbakken et al., 2011; Sannicandro and Cofano, 2017; Kuhn et al., 2019; Felion and DeBeliso, 2020), or core exercises combined with plyometrics and body strengthening (Vitale et al., 2018). These exercises were often performed in unstable conditions or in both stable and unstable conditions (Stanton et al., 2004; Sannicandro and Cofano, 2017; Vitale et al., 2018; Kuhn et al., 2019).

The assessment of athletic performance or measurement of functional movement variables was focused on throwing velocity (Saeterbakken et al., 2011; Kuhn et al., 2019; Felion and DeBeliso, 2020) and jumping performance (Vitale et al., 2018). Running economy was assessed with a test to exhaustion on a treadmill (Stanton et al., 2004). The core assessment included the Swiss Olympic test (Kuhn et al., 2019) and the Sahrmann core stability test (Stanton et al., 2004); dynamic balance was tested by means of Y-Balance test (Vitale et al., 2018); and jump abilities by using the side hop test, triple hop test, 6-m timed hop test, and the Sargent vertical jump test (Sannicandro and Cofano, 2017).

Core stability and core strength training have been used for the improvement of functional movement and consequently also athletic performance. The purpose of core stability exercises is to control the lumbar spine, whereas core strength exercises improve the transfer of muscle power, activation of local stabilizers, and global mobilizers (Saeterbakken et al., 2011; Sharrock et al., 2011; Sannicandro and Cofano, 2017). The training programs incorporating core stability exercises performed under stable or unstable conditions showed improvements in core muscle strength, muscular endurance, and body balance (Stanton et al., 2004; Vitale et al., 2018; Kuhn et al., 2019). However, there is a controversy as to whether an increase in core stability and strength is transferred to athletic performance.

For instance, a 6-week isolated resistance training program in young baseball players did not improve the throwing velocity in contrast to the ball-exit velocity (Felion and DeBeliso, 2020). Similar findings were found also after a 6-week core stabilization training in adult female handball players. Both experimental and control groups significantly increased throwing velocity of the jump throw, but their throwing velocity of the standing throw remained unchanged (Kuhn et al., 2019). Furthermore, an integrated short-term Swiss ball training failed to enhance the running economy measured by $\mathrm{VO}_{2} \max , \mathrm{vVO}_{2} \max$, or running economy at speeds of $60,70,80$, or $90 \% \mathrm{vVO}_{2} \max$ (Stanton et al., 2004). On the other hand, an isolated progressive core stability training in unstable conditions improved the throwing velocity significantly in young handball players (Saeterbakken et al., 2011). Also, an 8-week integrated neuromuscular training focused on core stability, plyometrics, and dynamic postural control led to an improvement of postural stability but not of jump performance in junior alpine skiers (Vitale et al., 2018). Furthermore, a 4-week integrated core stabilization program improved the one-leg jump abilities but not the bipedal vertical jump in the prepubertal athletes (Sannicandro and Cofano, 2017).

Depending on how the special core stabilization programs were integrated into standard training, it is possible to distinguish two variants, that is, either integrated programs conducted during warm-ups within a training session (Stanton et al., 2004; Sannicandro and Cofano, 2017; Vitale et al., 2018; Kuhn et al., 2019) or isolated additional programs carried out as the standard training (Felion and DeBeliso, 2020; Saeterbakken et al., 2011). With regard to these differences in integrated and isolated core stabilization training programs, findings in the literature are not consistent.

Most studies investigated the association of core stability with functional movements and athletic performance or the effect of specific core stabilization programs on functional movement and athletic performance in junior or younger age groups (Stanton et al., 2004; Nesser et al., 2008; Nesser and Lee, 2009; Chaudhari et al., 2011; Saeterbakken et al., 2011; Anand et al., 2017; Sannicandro and Cofano, 2017; Vitale et al., 2018; Felion and DeBeliso, 2020; de Bruin et al., 2021). However, only a few studies have investigated the role of core stability in the functional movement and athletic performance in adult athletes and the changes induced by core stabilization training (Abt et al., 2007; Chaudhari et al., 2011; Ozmen, 2016; Kuhn et al., 2019). The reason for this disproportionality could be the accessibility of young athletes compared to the elite ones for participating in intervention studies.

\section{Limitations in the Current Studies Investigating the Relationship Between Postural and/or Core Stability and Athlete Performance and Proposals for Further Research}

An analysis of the literature revealed several gaps in the existing studies (Table 3). There is still a lack of research that seeks to investigate the relationship of body balance and stability of the core with sport-specific performance. Although the importance of the core musculature for spine stabilization and postural control has been emphasized during the past decade, the supporting evidence is still scarce. Recently, increased research efforts have been accomplished to investigate effective exercise programs for improving spinal stability and body balance. Practitioners suggest that a strong core could contribute to better balance and proper posture with a positive impact on increasing their athletic performance and/or decreasing the occurrence of back pain. While postural and core stability may be a key factor in the prevention of musculoskeletal disorders, it seems that much less evidence exists on their role in sport-specific performance and related functional movements. These gaps revealed in the literature should be addressed in future studies. 
TABLE 3 | Research gaps identified in the literature and suggestions for future studies.

\section{Gaps and limitations revealed in the literature}

There is a lack of studies investigating the relationship between core stability or core strength and functional movement and/or athletic performance.

There is still inconsistent definition of core stability and core strength in spite of an increased number of studies in this field of research.

The research in this field has been conducted mainly in shooting, biathlon, archery, gymnastics, and team sports. More research has been carried out in team than individual sports.

Small sample sizes occur in most studies, which could reduce its power and increase the margin of error.

There are only few studies conducted on competitive athletes of a high performance level. The analysis of the literature in this scoping review related to the role of core stability in functional movement and/or athlete performance revealed that nine studies (69\%) were conducted with regularly competing high school or university athletes or athletes from lower competitions (Stanton et al., 2004; Abt et al., 2007; Chaudhari et al., 2011; Saeterbakken et al., 2011; Ozmen, 2016; Anand et al., 2017; Kuhn et al., 2019; Felion and DeBeliso, 2020; de Bruin et al., 2021), three studies (23\%) with young elite athletes (Nesser et al., 2008; Nesser and Lee, 2009; Vitale et al., 2018), and one study (8\%) with very young athletes (Sannicandro and Cofano, 2017).

Regarding the age of participants, eight studies (62\%) included adult athletes (Abt et al., 2007; Nesser et al., 2008; Nesser and Lee, 2009; Chaudhari et al., 2011; Ozmen, 2016; Anand et al., 2017; Kuhn et al., 2019; de Bruin et al., 2021) and five studies involved young athletes (Stanton et al., 2004; Saeterbakken et al., 2011; Sannicandro and Cofano, 2017; Vitale et al., 2018; Felion and DeBeliso, 2020).

There is a lesser number of research studies conducted on female than male participants. Regarding gender, the analysis of the literature related to the role of core stability in functional movement and/or athlete performance revealed that eight studies (62\%) included male athletes (Stanton et al., 2004; Abt et al., 2007; Nesser et al., 2008; Chaudhari et al., 2011; Ozmen, 2016; Anand et al., 2017; Vitale et al., 2018; Felion and DeBeliso, 2020), four studies (31\%) female athletes (Nesser and Lee, 2009; Saeterbakken et al., 2011; Kuhn et al., 2019; de Bruin et al., 2021), and one study (7\%) both girls and boys (Sannicandro and Cofano, 2017).

The control group is rarely included. Non-sporting population cannot be included in most of the studies because of the athletic performance tests used.

There is a missing information on the level of athlete performance.

General physical fitness tests rather than sport-specific tests are used.

Variables analyzed are not precisely described.

Experiments are conducted in different training periods (pre-season, in-season, post-season) what limits a comparison of findings.

The average duration of training programs is from 4 to 8 weeks while the training sessions vary from 25 to $30 \mathrm{~min}$, in some cases even from 60 to $75 \mathrm{~min}$, which very often combine balance, strength and core muscle exercises.

There is insufficient analysis of neuromuscular mechanisms underlying significant associations of postural and core stability with functional movement and/or athlete performance.

Balance, strength, plyometric or endurance exercises are usually associated with training induced improvements of postural and core stability but not with athlete performance.

\section{Suggestions for future studies}

In comparison with balance research, more attention should be paid to investigations related to the role of core stability and core strength in functional movement and/or athletic performance. The authors should use uniform terminology of core stability and core strength based on their characteristics, similarly as it is in the case of balance research.

As core stability and strength represent an integral part of athlete performance in sports based on lifting tasks and trunk rotations, their role in performance in acrobatic, combat, power and water sports should also be investigated.

The number of participants in research studies should be increased.

The research studies should include more elite athletes. In such a case, adults should be preferred over young participants.

The number of female participants should be increased.

The control group should be included, especially in intervention studies.

Information on the degree of physical development of athletes and their exposure to sport-specific tasks should be included. Better understanding the role of postural and core stability in athletic performance requires testing under conditions specific to a particular sport. Therefore, testing under sport-specific conditions should be preferred, particularly in athletes at a high level of competition.

Corresponding variables should be better specified in relation to functional movements in sports with high demands on postural and core stability.

Studies investigating the association of postural and core stability with functional movement and performance in athletes should be carried out during a period of their high level of sport-specific skills. The duration of training sessions and training programs should be separately specified for balance exercises and core stabilization or core strengthening exercises.

Greater attention should be paid to the interpretation of findings.

Further research is needed to investigate the relationship between postural or core stability and sport-specific performance and their changes after sport-specific training.

\section{CONCLUSION}

This scoping review revealed that among a variety of studies investigating the role of neuromuscular control of postural and core stability in functional movement and/or athlete performance, only a few revealed the relationships between them. Postural stability was found to play an essential role in performance in archery, biathlon, gymnastics, shooting, and team 
sports (e.g., basketball, hockey, soccer, tennis). Also, core stability and strength represent an integral part of athlete performance in sports based on lifting tasks and trunk rotations. Variables of these abilities are associated with performance-related skills in cricket, cycling, running, and team sports (e.g., baseball, football, hockey, netball, soccer, tennis). Better neuromuscular control of postural and core stability contribute to more efficient functional movements specific to particular sports. Training programs incorporating general and sport-specific exercises that involve the use of postural and core muscles showed an improvement of body balance, back muscle strength, and endurance. However, there is controversy about whether the improvement in these abilities is translated into athletic performance. Identifying the relationship of passive, active, and neural mechanisms underlying balance control and spinal posture with athlete performance would provide a basis for a multifaced approach in designing training and testing tools

\section{REFERENCES}

Aalto, H., Pyykkö, I., Ilmarinen, R., Kähkönen, E., and Starck, J. (1990). Postural stability in shooters. ORL J. Otorhinolaryngol. Relat. Spec. 52, 232-238. doi: $10.1159 / 000276141$

Abt, J. P., Smoliga, J. M., Brick, M. J., Jolly, J. T., Lephart, S. M., and Fu, F. H. (2007). Relationship between cycling mechanics and core stability. J. Strength Cond. Res. 21, 1300-1304. doi: 10.1519/R-21846.1

Agostini, V., Chiaramello, E., Canavese, L., Bredariol, C., and Knaflitz, M. (2013). Postural sway in volleyball players. Hum. Mov. Sci. 32, 445-456. doi: 10.1016/j. humov.2013.01.002

Akuthota, V., Ferreiro, A., Moore, T., and Fredericson, M. (2008). Core stability exercise principles. Curr. Sports Med. Rep. 7, 39-44. doi: 10.1097/01.CSMR. 0000308663.13278.69

Anand, P. C., Khanna, G. L., Chorsiya, V., Yadav, F., and Geomon, T. P. (2017). Relationship between core stability and throwing accuracy in cricket bowlers. Int. J. Sci. Res. 6, 13-14.

Andreeva, A., Melnikov, A., Skvortsov, D., Akhmerova, K., Vavaev, A., Golov, A., et al. (2021). Postural stability in athletes: the role of sport direction. Gait Posture 89, 120-125. doi: 10.1016/j.gaitpost.2021.07.005

Armstrong, R., Hall, B. J., Doyle, J., and Waters, E. (2011). Cochrane update. 'Scoping the scope' of a cochrane review. J. Public Health (Oxf) 33, 147-150. doi: 10.1093/pubmed/fdr015

Asseman, F., Caron, O., and Crémieux, J. (2004). Is there a transfer of postural ability from specific to unspecific postures in elite gymnasts? Neurosci. Lett. 358, 83-86. doi: 10.1016/j.neulet.2003.12.102

Asseman, F. B., Caron, O., and Crémieux, J. (2008). Are there specific conditions for which expertise in gymnastics could have an effect on postural control and performance? Gait Posture 27, 76-81. doi: 10.1016/j.gaitpost.2007.01.004

Ball, K. A., Best, R. J., and Wrigley, T. V. (2003). Body sway, aim point fluctuation and performance in rifle shooters: inter- and intra-individual analysis. J. Sports Sci. 21, 559-566. doi: 10.1080/0264041031000101881

Behm, D. G., Wahl, M. J., Button, D. C., Power, K. E., Kenneth, G., and Anderson, K. G. (2005). Relationship between hockey skating speed and selected performance measures. J. Strength Cond. Res. 19, 326-331. doi: 10. 1519/R-14043.1

Ben Moussa, A. Z., Zouita, S., Dziri, C., and Ben Salah, F. Z. (2012). Postural control in Tunisian soccer players. Sci. Sports 27, 54-56. doi: 10.1016/j.scispo.2011.03.006

Borzucka, D., Kręcisz, K., Rektor, Z., and Kuczyński, M. (2020a). Differences in static postural control between top level male volleyball players and nonathletes. Sci. Rep. 10:19334. doi: 10.1038/s41598-020-76390-x

Borzucka, D., Kręcisz, K., Rektor, Z., and Kuczyński, M. (2020b). Postural control in top-level female volleyball players. BMC Sports Sci. Med. Rehabil. 12:65. doi: 10.1186/s13102-020-00213-9 addressing postural and core stability in athletes under sportspecific conditions.

\section{AUTHOR CONTRIBUTIONS}

Both authors have made a substantial, direct, and intellectual contribution to the work, and approved it for publication.

\section{FUNDING}

This work was supported by the Scientific Grant Agency of the Ministry of Education, Science, Research and Sport of the Slovak Republic and the Slovak Academy of Sciences (No. 1/0089/20), the Slovak Research and Development Agency under the contract no. APVV-15-0704, and the Cross-border Co-operation Program INTERREG V-A SK-CZ/2018/06 (No. 304011P714) co-financed by the European Regional Development Fund.

Bringoux, L., Marin, L., Nougier, V., Barraud, P. A., and Raphel, C. (2000). Effects of gymnastics expertise on the perception of body orientation in the pitch dimension. J. Vestib. Res. 10, 251-258.

Busquets, A., Ferrer-Uris, B., Angulo-Barroso, R., and Federolf, P. (2021). Gymnastics experience enhances the development of bipedal-stance multisegmental coordination and control during proprioceptive reweighting. Front. Psychol. 12:661312. doi: 10.3389/fpsyg.2021.661312

Butler, R. J., Bullock, G., Arnold, T., Plisky, P., and Queen, R. (2016). Competitionlevel differences on the lower quarter Y-balance test in baseball players. J. Athl. Train. 51, 997-1002. doi: 10.4085/1062-6050-51.12.09

Caballero, C., Barbado, D., Hérnandez-Davó, H., Hernández-Davó, J. L., and Moreno, F. J. (2021). Balance dynamics are related to age and levels of expertise. Application in young and adult tennis players. PLoS One 16:e0249941. doi: 10.1371/journal.pone.0249941

Caballero, C., Barbado, D., Urbán, T., García-Herrero, J. A., and Moreno, F. J. (2020). Functional variability in team-handball players during balance is revealed by non-linear measures and is related to age and expertise level. Entropy (Basel) 22:822. doi: 10.3390/e22080822

Cè, E., Longo, S., Paleari, E., Riboli, A., Limonta, E., Rampichini, S., et al. (2018). Evidence of balance training-induced improvement in soccer-specific skills in U11 soccer players. Scand. J. Med. Sci. Sports 28, 2443-2456. doi: 10.1111/sms. 13240

Chapman, D. W., Needham, K. J., Allison, G., Lay, B., and Edwards, D. J. (2008). Effects of experience within a dynamic environment on postural control. Br. J. Sports Med. 42, 16-21. doi: 10.1136/bjsm.2006.033688

Chaudhari, A. M., McKenzie, C. S., Borchers, J. R., and Best, T. M. (2011). Lumbopelvic control and pitching performance of professional baseball pitchers. J. Strength Cond. Res. 25, 2127-2132. doi: 10.1519/JSC. 0b013e31820f5075

Croix, G., Chollet, D., and Thouvarecq, R. (2010). Effect of expertise level on the perceptual characteristics of gymnasts. J. Strength Cond. Res. 24, 1458-1463. doi: $10.1519 /$ JSC.0b013e3181d2c216

de Bruin, M., Coetzee, D., and Schall, R. (2021). The relationship between core stability and athletic performance in female university athletes. South Afr. J. Sports Med. 33, 1-9. doi: 10.17159/2078-516X/2021/v33ila10825

Edis, C., Vural, F., Vurgun, H. (2016). The importance of postural control in relation to technical abilities in small-sided soccer games. J. Hum. Kinet. 53, 51-61. doi: 10.1515/hukin-2016-0010

Edıs, C., Vural, F., Vurgun, H. (2017). Does running performance in small-sided games have a relation with postural control in youth soccer players? Turk. J. Sport Exe. 19, 83-91.

Era, P., Konttinen, N., Mehto, P., Saarela, P., and Lyytinen, H. (1996). Postural stability and skilled performance -3 a study on top-level and naive rifle shooters. J. Biomech. 29, 301-306. doi: 10.1016/0021-9290(95)00 066-6 
Felion, C. W., and DeBeliso, M. (2020). The effects of core training on high school baseball performance. Athens J. Sports. 7, 173-188. doi: 10.30958/ajspo.7-3-3

Glofcheskie, G. O., and Brown, S. H. M. (2017). Athletic background is related to superior trunk proprioceptive ability, postural control, and neuromuscular responses to sudden perturbations. Hum. Mov. Sci. 52, 74-83. doi: 10.1016/j. humov.2017.01.009

Halabchi, F., Abbasian, L., Mirshahi, M., Mazaheri, R., Shahi, M. H. P., and Mansournia, M. A. (2020). Comparison of static and dynamic balance in male football and basketball players. Foot Ankle Spec. 13, 228-235. doi: 10.1177/ 1938640019850618

Hrysomallis, C. (2011). Balance ability and athletic performance. Sports Med. 41, 221-232. doi: 10.2165/11538560-000000000-00000

Ihalainen, S., Kuitunen, S., Mononen, K., and Linnamo, V. (2016a). Determinants of elite-level air rifle shooting performance. Scand. J. Med. Sci. Sports 26, 266-274. doi: 10.1111/sms.12440

Ihalainen, S., Linnamo, V., Mononen, K., and Kuitunen, S. (2016b). Relation of elite rifle shooters' technique-test measures to competition performance. Int. J. Sports Physiol. Perform. 11, 671-677. doi: 10.1123/ijspp.2015-0211

Ihalainen, S., Laaksonen, M. S., Kuitunen, S., Leppävuori, A., Mikkola, J., Lindinger, S. J., et al. (2018). Technical determinants of biathlon standing shooting performance before and after race simulation. Scand. J. Med. Sci. Sports 28, 1700-1707.

Jadczak, Ł, Grygorowicz, M., Dzudziński, W., and Śliwowski, R. (2019a). Comparison of static and dynamic balance at different levels of sport competition in professional and junior elite soccer players. J. Strength Cond. Res. 33, 3384-3391. doi: 10.1519/JSC.0000000000002476

Jadczak, Ł, Grygorowicz, M., Wieczorek, A., and Śliwowski, R. (2019b). Analysis of static balance performance and dynamic postural priority according to playing position in elite soccer players. Gait Posture 74, 148-153. doi: 10.1016/j.gaitpost. 2019.09.008

Kim, M., Kim, Y., Kim, H., and Yoon, B. (2018). Specific muscle synergies in national elite female ice hockey players in response to unexpected external perturbation. J. Sports Sci. 36, 319-325. doi: 10.1080/02640414.2017.1306090

Ko, J. H., Han, D. W., and Newell, K. M. (2017). Skill level constrains the coordination of posture and upper-limb movement in a pistol-aiming task. Hum. Mov. Sci. 55, 255-263. doi: 10.1016/j.humov.2017.08.017

Ko, J. H., Han, D. W., and Newell, K. M. (2018). Skill level changes the coordination and variability of standing posture and movement in a pistol-aiming task. J. Sports Sci. 36, 809-816. doi: 10.1080/02640414.2017.1343490

Konttinen, N., Lyytinen, H., and Viitasalo, J. (1998). Rifle-balancing in precision shooting: behavioral aspects and psychophysiological implication. Scand. J. Med. Sci. Sports 8, 78-83. doi: 10.1111/j.1600-0838.1998.tb00172.x

Kuhn, L., Weberruß, H., and Horstmann, T. (2019). Effects of core stability training on throwing velocity and core strength in female handball players. J. Sports Med. Phys. Fitness 59, 1479-1486. doi: 10.23736/S0022-4707.18.09295-2

Lamoth, C. J., van Lummel, R. C., and Beek, P. J. (2009). Athletic skill level is reflected in body sway: a test case for accelometry in combination with stochastic dynamics. Gait Posture 29, 546-551. doi: 10.1016/j.gaitpost.2008.12.006

Lang, D., and Zhou, A. (2021). Relationships between postural balance, aiming technique and performance in elite rifle shooters. Eur. J. Sport Sci. doi: 10.1080/ 17461391.2021.1971775

Larue, J., Bard, C., Otis, L., and Fleury, M. (1989). Stability in shooting: the effect of expertise in the biathlon and in rifle shooting. Can. J. Sport Sci. 14, 38-45.

Leightley, D., Yap, M. H., Coulson, J., Piasecki, M., Cameron, J., Barnouin, Y., et al. (2017). Postural stability during standing balance and sit-to-stand in master athlete runners compared with nonathletic old and young adults. J. Aging Phys. Act. 25, 345-350. doi: 10.1123/japa.2016-0074

Liang, Y., Hiley, M., and Kanosue, K. (2019). The effect of contact sport expertise on postural control. PLoS One 14:e0212334. doi: 10.1371/journal.pone.0212334

Marcolin, G., Rizzato, A., Zuanon, J., Bosco, G., and Paoli, A. (2019). Expertise level influences postural balance control in young gymnasts. J. Sports Med. Phys. Fitness 59, 593-599. doi: 10.23736/S0022-4707.18.08014-3

Marsh, D. W., Richard, L. A., Williams, L. A., and Lynch, K. J. (2004). The relationship between balance and pitching error in college baseball pitchers. J. Strength Cond. Res. 18, 441-446. doi: 10.1519/R-13433.1

Mononen, K., Konttinen, N., Viitasalo, J., and Era, P. (2007). Relationship between postural balance, rifle stability and shooting accuracy among novice rifle shooters. Scand. J. Med. Sci. Sports 17, 180-185. doi: 10.1111/j.1600-0838.2006. 00549.x

Munzert, J., Müller, J., Joch, M., and Reiser, M. (2019). Specificity of postural control: comparing expert and intermediate dancers. J. Mot. Behav. 51, 259-271. doi: $10.1080 / 00222895.2018 .1468310$

Nesser, T. W., Huxel, K. C., Tincher, J. L., and Okada, T. (2008). The relationship between core stability and performance in division I football players. J. Strength Cond. Res. 22, 1750-1754. doi: 10.1519/JSC.0b013e3181874564

Nesser, T. W., and Lee, W. L. (2009). The relationship between core strength and performance in Division I female soccer players. J. Exerc. Physiol. 12, 21-28.

Olivier, A., Viseu, J.-P., Vignais, N., and Vuillerme, N. (2019). Balance control during stance - A comparison between horseback riding athletes and nonathletes. PLoS One 14:e0211834. doi: 10.1371/journal.pone.0211834

Omorczyk, J., Bujas, P., Puszczałowska-Lizis, E., and Biskup, L. (2018). Balance in handstand and postural stability in standing position in athletes practicing gymnastics. Acta Bioeng. Biomech. 20, 139-147.

Opala-Berdzik, A., Głowacka, M., and Juras, G. (2021). Postural sway in young female artistic and acrobatic gymnasts according to training experience and anthropometric characteristics. BMC Sports Sci. Med. Rehabil. 13:11. doi: 10. 1186/s13102-021-00236-w

Ozmen, T. (2016). Relationship between core stability, dynamic balance and jumping performance in soccer players. Turk. J. Sport Exerc. 8, 110-113. doi: 10.15314/tjse. 93545

Paillard, T. (2019). Relationship between sport expertise and postural skills. Front. Psychol. 10:1428. doi: 10.3389/fpsyg.2019.01428

Paillard, T., Noé, F., Rivière, T., Marion, V., Montoya, R., and Dupui, P. (2006). Postural performance and strategy in the unipedal stance of soccer players at different levels of competition. J. Athl. Train. 41, 172-176.

Pau, M., Arippa, F., Leban, B., Corona, F., Ibba, G., Todde, F., et al. (2015). Relationship between static and dynamic balance abilities in Italian professional and youth league soccer players. Phys. Ther. Sport 16, 236-241. doi: 10.1016/j. ptsp.2014.12.003

Pau, M., Porta, M., Arippa, F., Pilloni, G., Sorrentino, M., Carta, M., et al. (2018). Dynamic postural stability, is associated with competitive level, in youth league soccer players. Phys. Ther. Sports 35, 36-41. doi: 10.1016/j.ptsp.2018.11.002

Platzer, H.-P., Raschner, C., and Patterson, C. (2009a). Performance-determining physiological factors in the luge start. J. Sports Sci. 27, 221-226. doi: 10.1080/ 02640410802400799

Platzer, H.-P., Raschner, C., Patterson, C., and Lembert, S. (2009b). Comparison of physical characteristics and performance among elite snowboarders. J. Strength Cond. Res. 23, 1427-1432. doi: 10.1519/JSC.0b013e3181aald9f

Puszczałowska-Lizis, E., and Omorczyk, J. (2019). The level of body balance in standing position and handstand in seniors athletes practicing artistic gymnastics. Acta Bioeng. Biomech. 21, 37-44.

Reeves, N. P., Narendra, K. S., and Cholewicki, J. (2007). Spine stability: the six blind men and the elephant. Clin. Biomech. (Bristol, Avon) 22, 266-274. doi: 10.1016/j.clinbiomech.2006.11.011

Rivera, C. E. (2016). Core and lumbopelvic stabilization in runners. Phys. Med. Rehabil. Clin. North Am. 27, 319-337. doi: 10.1016/j.pmr.2015.09.003

Sadowska, D., Sacewicz, T., Lichota, M., Krzepota, J., and Ładyga, M. (2019). Static postural balance in modern pentathletes: a pilot study. Int. J. Environ. Res. Public Health 16:1760. doi: 10.3390/ijerph16101760

Saeterbakken, A. H., Van den Tillaar, R., and Seiler, S. (2011). Effect of core stability training on throwing velocity in female handball players. J. Strength Cond. Res. 25, 712-718. doi: 10.1519/JSC.0b013e3181cc227e

Sannicandro, I., and Cofano, G. (2017). Core stability training and jump performance in young basketball players. Int. J. Sci. Res. 6, 479-482. doi: 10. 21275/ART20173282

Sarro, K. J., Viana, T. C., and De Barros, R. M. L. (2021). Relationship between bow stability and postural control in recurve archery. Eur. J. Sport Sci. 21, 515-520. doi: 10.1080/17461391.2020.1754471

Sharrock, C., Cropper, J., Mostad, J., Johnson, M., and Malone, T. (2011). A pilot study of core stability and athletic performance: is there a relationship? Int. J. Sports Phys. Ther. 6, 63-74.

Snyder, N., and Cinelli, M. (2020). Comparing balance control between soccer players and non-athletes during a dynamic lower limb reaching task. Res. Q. Exerc. Sport 91, 166-171. doi: 10.1080/02701367.2019.1649356 
Sobera, M., Serafin, R., and Rutkowska-Kucharska, A. (2019). Stabilometric profile of handstand technique in male gymnasts. Acta Bioeng. Biomech. 21, 63-71.

Spancken, S., Steingrebe, H., and Stein, T. (2021). Factors that influence performance in Olympic air-rifle and small-bore shooting: a systematic review. PLoS One 16:e0247353. doi: 10.1371/journal.pone.0247353

Spratford, W., and Campbell, R. (2017). Postural stability, clicker reaction time and bow draw force predict performance in elite recurve archery. Eur. J. Sport Sci. 17, 539-545. doi: 10.1080/17461391.2017.1285963

Stambolieva, K., Diafas, V., Bachev, V., Christova, L., and Gatev, P. (2012). Postural stability of canoeing and kayaking young male athletes during quiet stance. Eur. J. Appl. Physiol. 112, 1807-1815. doi: 10.1007/s00421-011-2151-5

Stanton, R., Reaburn, P. R., and Humphries, B. (2004). The effect of short-term Swiss ball training on core stability and running economy. J. Strength Cond. Res. 18, 522-528.

Verhoeven, F. M., and Newell, K. M. (2016). Coordination and control of posture and ball release in basketball free-throw shooting. Hum. Mov. Sci. 49, 216-224. doi: 10.1016/j.humov.2016.07.007

Vitale, J. A., La Torre, A., Banfi, G., and Bonato, M. (2018). Effect of an 8-week body weight neuromuscular training on dynamic balance and vertical jump performance in elite junior skiing athlets: a randomized control trial. J. Strength Cond. Res. 32, 911-920. doi: 10.1519/JSC.0000000000002478

Wells, G. D., Elmi, M., and Scott Thomas, S. (2009). Physiological correlates of golf performance. J. Strength Cond. Res. 23, 741-750. doi: 10.1519/JSC. 0b013e3181a07970

Whitney, S. L., Roche, J. L., Merchetti, G. F., Lin, C. C., Steed, D. P., Furman, G. R., et al. (2011). A comparison of accelerometry and center of pressure measures during computerized dynamic posturography: a measure of balance. Gait Posture 33, 594-599. doi: 10.1016/j.gaitpost.2011.01.015
Willardson, J. M. (2007). Core stability training: applications to sports conditioning programs. J. Strength Cond. Res. 21, 979-985. doi: 10.1519/R-20255.1

Zago, M., Moorhead, A. P., Bertozzi, F., Sforza, C., Tarabini, M., and Galli, M. (2020). Maturity offset affects standing postural control in youth male soccer players. J. Biomech. 99:109523. doi: 10.1016/j.jbiomech.2019.109523

Zazulak, B. T., Hewett, T. E., Reeves, N. P., Goldberg, B., and Cholewicki, J. (2007). Deficits in neuromuscular control of the trunk predict knee injury risk - a prospective biomechanical-epidemiologic study. Am. J. Sports Med. 35, 1123-1130. doi: 10.1177/0363546507301585

Zemková, E. (2014). Sport-specific balance. Sports Med. 44, 579-590. doi: 10.1007/ s40279-013-0130-1

Conflict of Interest: The authors declare that the research was conducted in the absence of any commercial or financial relationships that could be construed as a potential conflict of interest.

Publisher's Note: All claims expressed in this article are solely those of the authors and do not necessarily represent those of their affiliated organizations, or those of the publisher, the editors and the reviewers. Any product that may be evaluated in this article, or claim that may be made by its manufacturer, is not guaranteed or endorsed by the publisher.

Copyright (c) 2022 Zemková and Zapletalová. This is an open-access article distributed under the terms of the Creative Commons Attribution License (CC BY). The use, distribution or reproduction in other forums is permitted, provided the original author(s) and the copyright owner(s) are credited and that the original publication in this journal is cited, in accordance with accepted academic practice. No use, distribution or reproduction is permitted which does not comply with these terms. 